\title{
Contribución al conocimiento de algunas producciones en hueso de la ciudad hispanorromana de Complutum: el caso de las acus crinales
}

\author{
S. Rascón Marqués*, J. Polo lópez, G. Pedreira Campillo, \\ P. ROMÁN VICENTE
}

\section{RESUMEN}

Se presentan en este trabajo algunos elementos que conformaron el aderezo personal femenino en el mundo romano, como fue el caso de las acus crinales. El estudio analiza la aparición de estos elementos y la presencia de ellos en las fuentes clásicas, para pasar a estudiar los ejemplos aparecidos en la ciudad hispanorromana de Complutum, en contextos estratigráficos bien datados. Además se abordan aspectos fundamentales y hasta la fecha inéditos como la tecnología y la producción, acompañados de un análisis tipológico pormenorizado que contribuya a caracterizar los elementos de este tipo, hasta la fecha meros números de inventario en las memorias de excavación.

Palabras clave: Instrumenta domestica, acus crinales, agujas, hueso, Complutum.

\section{ABSTRACT}

The present paper focus a particular aspect of roman femenine adornment, the so called acus crinales. The study begins with an updated view

\footnotetext{
* El presente estudio, se inscribe bajo los trabajos que se vienen desarrollando sobre la industria en hueso de la ciudad hispanorromana de Complutum, dentro del proyecto del TallerEscuela de Arqueología y Rehabilitación (TEAR) del Exmo. Ayuntamiento de Alcalá de Henares, Paseo del Juncal, s/n. Apdo. 256. 28802 Alcalá de Henares. Queremos agradecer a D. ANTONio MÉNDEZ MADARIAGA, el habemos permitido acceder a la colección de materiales aquí presentados, así como al Dr. D. Ángel FuENTES Domínguez por la ayuda desinteresada que sin duda enriqueció de manera notable el presente trabajo.
} 
of their presence through classical texts, followed by the tipological analysis of the collection recovered at the roman city of Complutum (Alcala de Henares, Spain). Other aspects are discussed, such as technology and production, as a contribution to the characterization of this type of items.

Key words: Instrumenta domestica, acus crinales, head pins, bone, Complutum.

\section{INTRODUCCIÓN}

«acus sunt quibus in feminis ornandorum crinium compago retinetur, ne laxius fluant et sparsos dissipentur capillos» 1.

Isid. Orig, XIX, 31, 9

Sin duda uno de los hallazgos, si no excesivamente abundantes, sí constantes en cualquier excavación de época romana son las denominadas acus crinales, o alfileres para el cabello realizados en distintos materiales, pero principalmente en hueso, asta o bronce.

Aunque tradicionalmente el uso que se viene atribuyendo a este tipo de objetos es el de sujetar los cabellos de las mujeres romanas, tal y como expresa la voz latina con las que se las denomina, casi con total seguridad se debieron emplear con otras funciones que en muchas ocasiones resultan ciertamente difíciles de determinar, ya que son pocos los elementos que nos permiten establecer si una de estas piezas estuvo destinada a formar parte de un moño o un tocado de una dama romana, sujetar prendas de vestir, o simplemente servir como un aplicador de perfumes.

Es por esta razón por la que deberemos mostrarnos cautelosos a la hora de interpretar estos materiales, y limitarnos a sugerir en la medida de nuestras posibilidades la función a la que estuvieron destinados.

\section{EL CONTEXTO ARQUEOLÓGICO}

La totalidad de los materiales que sirven de fundamento a nuestro estudio proceden de las excavaciones arqueológicas desarrolladas en

1 Con las agujas se mantiene el moño en el peinado de las mujeres para que los cabellos no cuelguen sueltos y aparezcan alborotados. 
Complutum a lo largo de los últimos diez años. Hemos obviado los materiales procedentes de las campañas anteriores a 1984, que ya fueron convenientemente publicadas en la correspondiente memoria de excavación (Fernández Galiano, 1984) ${ }^{2}$.

Como primer enclave hemos elegido el «complejo termal de Hippolytus" (Rascón, Polo y Maeso, 1996), excavado por nosotros desde el año 1990 y cuya cronología ofrece dos momentos bien diferenciados, el más antiguo que va desde los años centrales del siglo I d.C. hasta los primeros años del siglo \| d.C. y el más reciente que arrancaría desde la mitad del siglo ill d.C. o principios del iv d.C. (Rascón, Polo, Méndez y Gómez, 1995) y se corresponde con la fase constructiva de mayor monumentalidad, en la que se pudo documentar la presencia de varios mosaicos (Rascón, Polo, Méndez y Gómez, 1995). La funcionalidad del edificio fue de carácter termal, pero una serie de consideraciones nos llevan a interpretarlo como un collegium iuvenum (Rascón Marqués, 1995).

La denominada «Casa de los Estucos» se define como una domus en la zona foral complutense, estando ubicada a tan sólo unas decenas de metros del Foro de la ciudad. Es uno de los edificios de cronología menos precisa de cuantos se han excavado en Complutum. La fecha de construcción del edificio hay que proponerla en la segunda mitad del siglo I d.C., algo posterior al levantamiento de los edificios públicos, que se produce en época de Claudio/Nerón. La fecha de abandono es de difícil precisión, en todo caso no anterior al siglo $V$ (Méndez y Rascón, 1989, 180)

El siguiente enclave del entorno complutense que hemos incluido en este estudio es el denominado «Fuente del Juncal», que no está definido como un edificio concreto, sino como una espacio con diversas estructuras que no tienen una sola entidad arquitectónica. Los niveles arqueológicos se hallaban extremadamente alterados y revueltos, lo que se explica por la cercanía de la confluencia de los ríos Henares y Camarmilla. A pesar de ello se localizan unas estructuras relacionadas con un nivel de inicios de época julio-claudia, con algunos materiales que podían incluso retrotraerse a época augustea, datos estos muy importantes para comprender el traslado del asentamiento en el cerro de San Juan del Viso, donde se ubica la ciudad celtíbero-romana (Fernández Galiano, 1976, 103; Fernández Galiano, 1984, 393), a la nova urbs, la Complutum del llano

\footnotetext{
2 No queremos dejar pasar esta oportunidad para agradecer desde estas páginas, las sugerencias hechas a este estudio por el Dr. FERNÁNDEZ-GaLIANO, quien con infinita amabilidad accedió en todo momento a las cuestiones por nosotros planteadas.
} 
cuyo centro gira en torno al área denominada en la actualidad como «Paredón del Milagro».

\section{LAS ACUS CRINALES EN LAS FUENTES GRIEGAS Y LATINAS}

Con el fin de ubicar este tipo de objetos en su contexto funcional diremos que en época romana formaron parte del grupo de instrumentos que eran exclusivos del mundus muliebris (o mundo de la mujer). Este término aparece muy bien definido gracias al testimonio de los jurisconsultos romanos (Dig, XXXIV, 2, 25), los que a la hora de realizar los listados cronológicos de las emperatrices romanas nos ofrecieron importantes datos para valorar los objetos destinados al adorno y aseo femenino. De cualquier manera la expresión mundus muliebris designó exclusivamente, a todos aquellos elementos que se vinculaban directamente con el cuidado y mantenimiento del cuerpo de la mujer, incluyendo elementos para el baño, perfumes, ungüentos, espejos y cajas (Ladjimi-Sebai, 1985, 56).

Por otra parte vamos a encontrar un segundo término, la expresión de ornamentum, con la que se designaba a los elementos que servían a la mujer para resaltar su belleza exterior. Dentro de esta expresión se incluía cualquier tipo de accesorio que realzara el peinado y la vestimenta de la mujer, así como también las joyas y como no, las acus ya que éstas eran un elemento indispensable para la elaboración y ornamento del peinado, y que en algunos casos también fueron utilizadas como fíbulas para la sujeción y adorno de la vestimenta.

Esta división, obtenida gracias al testimonio de los juristas romanos (Dig, XXXIV, 2, 25) entre los conceptos de mundus muliebris y ornamentum $^{3}$ fue muy pronto abandonada, y ambos términos se constituyeron como un elemento único, dentro del cual se agrupaba todo aquello que estuviese directamente relacionado con el mundo de la mujer (Ladjimi-Sebai, $1985,57)$.

Pese a que, hasta el momento, nos hemos referido a las acus crinales como algo exclusivamente relacionado con el mundo femenino, debemos considerar que en períodos anteriores al que nos ocupa, estos elementos fueron también utilizados por el hombre, ya que al ser una de sus funciones

\footnotetext{
3 A esta división también deberíamos incorporar la expresión vestis que hacía referencia a aquellos elementos que intervenian en la vestimenta de la mujer romana.
} 
específicas la sujeción del cabello, su uso fue adaptado por aquellos en algunos momentos en los que la moda impuso el pelo largo (Daremberg y Saglio, 1969, 63). Un testimonio de esto último nos lo ofrece Ovidio en el Ars Amandi, donde el autor hace una referencia a los largos cabellos de Teseo, indicando que éste se presento ante la hija de Minos, sin haberse sujetado la cabellera a las sienes con horquillas, referencia que a continuación transcribimos literalmente:

«Minida Theseus abstulit, a nulla tempora comptus acu»

Ovidio, Ars Am., I, 510

También Homero en la lliada nos describe a un hombre que presenta sus cabellos ornados con joyas de oro y de plata (Homero, lliada, XVII, 52). Sabemos también que los atenienses, poco después de las Guerras Médicas, se sujetaban los cabellos por medio de unas agujas que aparecían decoradas con cigarras de oro (Daremberg y Saglio, 1969, 63).

Sin embargo en el mundo romano el hombre ha dejado ya de llevar el pelo largo, convirtiéndose el pelo en un signo de distinción, por lo que las acus crinales, ya carentes de utilidad para él, pasan a ser un instrumento utilizado exclusivamente por la mujer.

En cuanto al empleo de estas agujas para elaborar los peinados, se debieron destinar a modo de separador, para dividir los cabellos, acus discernicula o acus discriminales (Daremberg y Saglio, 1969, 63). Debieron ser, estos elementos un instrumento indispensable para la ornatrix, que era la persona especializada en elaborar el tocado o peinado de la señora romana. Estas ornatrices eran las esclavas que la señora destinaba exclusivamente a la elaboración de su peinado, aunque también estaban consideradas como auxiliares para su aseo y arreglo personal. Debieron ser personajes con una alta especialización, tal y como lo demuestran algunas inscripciones, como la documentada en Argelia, en la que se nos trasmite incluso la existencia de ayudantes - subornatrices, lo que nos esta refiriendo la existencia de una fuerte jerarquía dentro del mundo de estos profesionales (Ladjimi-Sebai, $1985,63)$.

Las referencias clásicas resultan bastante amplias en este sentido, no obstante hemos recurrido de nuevo a Ovidio ya que nos ofrece un interesante testimonio, por un lado sobre el trabajo de la ornatrix, como del empleo de las acus por parte de esta, así en su obra «Amores» nos dice textualmente: 
«non acus abrupit, non uallum pectinis illos;

ornatrix tuto corpore semper erat

ante meos saepe est oculos ornata nec umquam

bracchia derepta sucia fecit acu» ${ }^{4}$.

Ovidio, Am. I, 14 a 18

Desde el punto de vista arqueológico, se ha podido documentar una de estas acus discriminales, labrada junto con un peine sobre una lápida funeraria de una ornatrix, y que aparece como símbolo identificativo de la profesión, lo que avala plenamente la idea de que estas son instrumentos que aparecen directamente relacionados con la elaboración del tocado o peinado (Daremberg y Saglio, 1969, 63; Beal, 1983a, 184).

No obstante el uso fundamental de estos alfileres fue el ser utilizados como elementos para la sujeción del peinado, sobre todo en el caso de los grandes tocados que según la época y momento se irán poniendo de moda en el mundo romano, y que hará esencial el uso de las acus crinales, como elementos de sustentación para esos enormes edificios en los que se convertirán los peinados creados mediante el entrecruzamiento de los cabellos, que para la señora romana van a ser un elemento indispensable para realzar su belleza y su posición social. El tocado o peinado era para la mujer romana un elemento de adorno fundamental, al igual que lo eran las joyas o la vestimenta, por lo que pondrán mucho interés en el cuidado de sus cabellos, convirtiéndolos la mayor parte de las veces en autenticas obras de arte.

La mujer romana debía llevar el pelo lo suficientemente largo para poder recogerlo, y siempre debía presentarse con el pelo recogido ya que el pelo suelto suponía un elemento descalificador, y se consideraba un rasgo de abandono y descuido (Mariné, 1983, 60). Es en este sentido en el que debemos ubicar el testimonio de Isidoro de Sevilla que utilizábamos para introducir nuestro trabajo, en el que el autor afirma que los cabellos de la mujer deben estar recogidos y no alborotados (Isid. Orig, XIX, 31,9). Para poder recogerse el pelo la mujer necesitaba de numerosos elementos, como cintas, hilos y, como no, también de acus crinales. Pero estas no sólo van a tener un carácter funcional, sino que frecuentemente servían como un elemento más de adorno, dado que no se podía nunca desaprovechar la oportunidad para acrecentar la belleza de la mujer, por eso

4 Que según traducción de PALACIOS MARTiN leemos de la siguiente manera: «No los arrancaban las horquillas, ni los dientes del peine; la peinadora nunca tuvo que padecer por elto. Más de una vez fue peinada ante mis propios ojos y nunca sus brazos sufrieron picotazos con la horquilla». 
en muchas ocasiones nos vamos a encontrar con agujas de pelo que son verdaderas joyas y un espléndido desarrollo de la habilidad artesanal y no en pocas ocasiones realizadas con materiales nobles como oro, plata o marfil. De esta forma Marcial, en uno de sus epigramas se refiere a una de estas acus de la siguiente manera:

"Acus Aurea"

«Splendida ne maldivi violent bombycina crines,

figat acus tortas sustineatque comas» ${ }^{5}$.

Marcial. Ep, XIV, 24.

De cualquier manera los testimonios en la literatura clásica avalan de sobrada manera, el uso de las acus como agujas o alfileres para el cabeIlo. A los ya citados habría que añadir otras citas como las referidas por Marcial (Ep, II, 66), Ovidio (Ars. Am, I, 150), Silio Itálico (Sil. XV, 16), Domitio Ulpiano (Dig. XXXIV, 2, 25, 10), Apuleyo (Met. VIII, 13).

En cuanto a los testimonios puramente arqueológicos, sabemos que estas manufacturas han sido documentadas en numerosos yacimientos de todo el imperio, pero será en las necrópolis de inhumación donde la presencia de estos alfileres clarifique en mayor medida su funcionalidad, ya que suelen aparecer alrededor del cráneo (lo que nos indica que fueron usadas para la sujeción de los cabellos), aunque también se han registrado a los pies del esqueleto, bien de manera aislada o recogidas en el interior de estuches o cajas (Beal, 1983a, 183).

Queremos citar en primer lugar el testimonio del mismo Complutum, donde en una de las sepulturas tardoantiguas del Camino de los Afligidos se encontraron tres acus en torno al cráneo, si bien en este caso se trataba de agujas de bronce (Méndez y Rascón, 1989, 223).

Por su parte también debemos hacer referencia a hallazgos como los de York, donde se encontró el cuerpo de una mujer que conservaba en la parte posterior de la cabeza un moño sujeto con numerosas acus crinales realizados en azabache (MacGregor, 1985, 113), o los también clarificadores de Fayoum, en donde se halló una banda de cabellos postizos, que debido a las favorables condiciones climatológicas pudieron conservarse y llegar hasta nuestros días. Esta banda presentaba más de sesenta acus

5 Que podríamos traducir siguiendo la transcripción que propone DuLCE ESTEFANIA de la siguiente manera: «Aguja de oro», «Para que los cabellos de quien los llevan perfumados no manchen sus vestidos, que esta aguja sujete y sostenga su rizada cabellera». 
crinales de bronce, que estaban elaborando el entrecruzamiento de cabellos, creando de esta manera un peinado muy complejo que posteriormente se ceñiría a la cabeza a modo de postizo (Beal, 1983a, 184).

También las acus aparecen entre los cabellos en los retratos monetales de Helena, mujer de Constancio Cloro, y de la mujer de Valentiniano III, Licinia Eudoxia, tal y como nos ha hecho saber G. R. Davidson (Beal, 1983a,183). Del mismo modo, otro elemento que nos prueba el uso de estos objetos como medio de sujeción del cabello, es una estatua femenina que según E. Saglio fue hallada en el siglo XVIII cerca de Apt, Vaucluse, de la que desgraciadamente desconocemos su paradero, que presentaba un moño o recogido muy voluminoso, compuesto a base de trenzas que se sujetaban gracias a una enorme acus, cuya cabeza presentaba decoración en forma de anilla (Daremberg y Saglio, 1969, 64).

\section{DIFERENTES FUNCIONALIDADES DE LAS ACUS CRINALES}

Probablemente este tipo de manufacturas debieron tener otras utilidades, aparte de las relacionadas directamente con el mundo del peinado. De esta manera siguiendo el testimonio de Juvenal podemos establecer un posible empleo de estos elementos fuera del contexto en el que los hemos venido incluyendo hasta el momento, y en este caso más próximo al mundus muliebris. Este nuevo uso al que nos referimos es el de emplear una aguja o alfiler para la aplicación de tintes o cosméticos sobre el rostro, con el objeto de disimular los defectos de este, o servir como aplicador de maquillaje (hollín humedecido) sobre las cejas (Juvenal, Sat. II, 94).

En ocasiones resulta bastante frecuente encontrar bajo la denominación de acus algunas piezas que casi con total seguridad fueron utilizadas como aplicadores de perfumes y de ungüentos, lo que nos llevaría a tener que incluirlas no en la categoría de las acus sino en la de las ligulae, pequeñas cucharillas, o aplicadores (Lám V. Núm 103) cuya posible utilización resulta una cuestión compleja, ya que pudieron ser utilizadas como sondas para los oídos.

A modo de anécdota, recogemos otro posible uso de las acus que se constata también en la literatura clásica, y es su utilización como arma punzante o de tortura (Ávila França, 1968; Daremberg y Saglio, 1969). Las agujas de pelo se convirtieron en armas muy peligrosas en manos de las mujeres crueles y vengativas, que no dudaron en ningún momento en usarlas para castigar a sus esclavos ante la más leve falta, utilizando las agujas para herirles en los brazos y mejillas (Ovidio, Ars Am. III, 240; 
Ovidio, Amor. I, 14; Petronio, Sat. 21). Por su parte Apuleyo (Metam. VIII, 13) nos cuenta cómo una mujer con la ayuda de una de estas agujas vengó la muerte de su marido, al clavarla en los ojos del asesino. Así como Dión Casio (XLVII, 8) de la misma manera, se refiere a cómo la mujer de Marco Antonio, Fulvia, teniendo en sus rodillas la cabeza de Cicerón asesinado, le clavó en la lengua una de las horquillas que tenía entre sus cabellos.

Por último podemos citar que algunas de las supuestas acus debieron ser usadas como elementos de sujeción del vestido, asociadas con túnicas y capas a modo de fíbulas (MacGregor, 1985; Stevenson, 1955), como las piezas cubiertas con láminas de oro a las que a continuación haremos referencia (MacGregor, 1985, 70).

\section{MATERIALES EMPLEADOS Y PROCESO DE FABRICACIÓN}

Las acus fueron elaboradas sobre diversos tipos de materiales, dentro de los cuales los más usuales fueron el hueso o asta, o metales como el bronce (Beckmann, 1966; Stevenson, 1955) e incluso hierro, aunque tenemos pocos testimonios de este último (Alarçao; Etienne; Delgado; Mayet y Moutinho, 1979). No obstante casi con total seguridad debieron existir manufacturas de este tipo realizadas en materiales perecederos como la madera, de las que desgraciadamente no hemos podido documentar ningún ejemplo (Ávila França, 1968, 67). Pero del mismo modo que fueron utilizados para la realización de estas manufacturas materiales comunes, también se emplearon materiales nobles como marfil, azabache (MacGregor, 1985, 113), oro (Marc. Ep. II, 66) y plata (Ávila França, 1968, 67). Incluso hemos podido constatar el uso de finas láminas de oro para recubrir el cuerpo de algunas manufacturas realizadas en hueso (MacGregor, 1985; Beal, 1983a).

Lo primero que debemos tener en cuenta a la hora de plantearnos cuestiones relacionadas con la fabricación de objetos en hueso en época romana es sin duda, la importante ausencia de elementos que nos permitan una correcta valoración, tanto de la actividad artesanal como de las manufacturas realizadas en este material. Pese a esto podemos intuir que los procesos de fabricación de las distintas manufacturas en hueso no debieron ser muy diferentes en los distintos puntos del Imperio, ni por supuesto variar mucho en el transcurso de la época que nos ocupa (Beal, 1983b, 607).

Desafortunadamente, carecemos de testimonios en el ambiente de 10 iconográfico y especialmente de lo funerario (estelas o inscripciones) que, 
en otras manifestaciones del trabajo artesanal, han resultado de gran interés a la hora de valorar hechos como la consideración social de estas actividades, o su desarrollo técnico. Las únicas referencias escritas sobre esta industria se las debemos a Plutarco y tienen poco que ver con el caso concreto de la fabricación de acus crinales.

Recurriendo al testimonio arqueológico que, aunque no abundante, puede resultar lo bastante clarificador, podemos referirnos a hallazgos, como los de la iglesia de Santa María en la ciudad de Beja, que constituye uno de los únicos ejemplos en la Península de posible lugar dedicado a la fabricación de manufacturas en hueso, y más concretamente de acus crinales (Viana, 1944), los realizados en yacimientos franceses como Alesia y Champallement (Beal, 1983a, 20), los más recientes de la villa de Vienne (Beal, sin fecha), o los hallazgos procedentes de Inglaterra y Escocia publicados por MacGregor (MacGregor, 1985), que sin duda nos ofrecerán una idea bastante aproximada de lo que pudo ser este tipo de actividad en época romana.

Por nuestra parte debemos apuntar que en la denominada "Casa de los Estucos», ubicada dentro del entorno complutense, podríamos contar también con uno de estos talleres dedicados a la manufactura del hueso, debido al gran volumen de hallazgos que han sido documentados. Actualmente esta cuestión esta siendo objeto de estudio que esperamos en un futuro pueda servirnos para determinar la veracidad o no de esta hipótesis.

Entre los procesos que intervienen en la elaboración de las manufacturas en hueso -desde la preparación de la materia prima (hueso o asta)destacaremos el cortado, el tallado, el alisado y el refinado, el grabado, el perforado, el torneado, el remachado o incluso el teñido- (MacGregor, 1985; Beal, 1983a; Viana, 1944). No obstante sólo haremos referencia a aquellos procedimientos que creemos intervienen en la fabricación de acus crinales. Estos procesos o etapas a las que no referimos son los siguientes (Viana, 1944, 400):

a) Separación de la epífisis del hueso, ya que ésta no parece tener aprovechamiento industrial.

b) Corte transversal del cuerpo del hueso en fragmentos de tamaño similar al de la pieza que se pretende obtener.

c) Corte longitudinal de las piezas resultantes del proceso anterior.

d) Desbastado, hasta que adquiera la forma deseada.

e) Pulido y acabado. Proceso este último en que podríamos incluir el hecho de que se tiñan algunas piezas o la propia ejecución de la decoración. 
Dichos procedimientos sólo pueden ser constatables a partir de las huellas de fabricación reconocidas sobre las propias manufacturas, sobre los restos de industria (Beal, 1983a, Beal, sin fecha; MacGregor, 1985; Johnson, 1972), o en aquellos yacimientos en los que se hallan encontrado herramientas que de alguna manera pudieran estar relacionadas con la realización de objetos en hueso.

En cuanto al primero de los procesos, es decir la preparación del hueso para su posterior trabajo, las piezas óseas empleadas con más frecuencia corresponden a huesos largos como tibias o fémures, metatarsos o metacarpos, generalmente de bóvido (Beal, sin fecha, 5; Alarçao, Etienne, Moutinho y Ponte, 1979, 126), aunque no exclusivamente, ya que en las zonas de ambiente boscoso o simplemente próximos a éste presentan un elevado porcentaje de estas manufacturas en asta.

Una vez obtenida la pieza se procedía a su preparación para el trabajo (previa limpieza del hueso que seguramente se realizaría mediante la utilización de cal viva), es decir a la separación de la epífisis o extremos de los huesos (Beal, sin fecha, 5) como parecen atestiguar los extremos de tibias y fémures de bóvido hallados en la ciudad de Beja (Viana, 1944), concretamente una extremidad superior de un fémur, cuatro extremidades inferiores de fémures y seis cabezas de tibia, estas últimas serradas más cerca de la epífisis para de esta manera obtener un mayor aprovechamiento del cuerpo dei hueso ${ }^{6}$.

La separación de la epífisis, dado que resulta demasiado porosa y por tanto inutilizable para la realización de este tipo de manufacturas, se realizaría a través del serrado, que es el procedimiento más usual para cortar el hueso, aunque como veremos no el único (Beal, 1983a, 23; MacGregor, $1985,55)$.

En último lugar se procedería al almacenamiento de la misma, tal y como parecen atestiguar algunos de los hallazgos a los que hacíamos referencia (Beal, sin fecha).

Los cortes a los que serán sometidos las piezas de hueso podrán ser bien transversales (de los que se obtendría una porción de hueso de una longitud aproximada a la de la pieza deseada), en cuyo caso la operación se realizará con la ayuda de una sierra, o bien longitudinales, que según Beal se realizarían probablemente con martillo y cincel (Beal,

\footnotetext{
- Además de los hallazgos citados, se hallaron en Beja una sección transversal de la tibia de un bóvido, dos piezas longitudinales, también de bóvido y un Acus crinalis a mitad del proceso de fabricación.
} 
1983a, 25), o con la ayuda de las cuñas metálicas que harían saltar esquirlas del núcleo de hueso que constituirían el cuerpo de las futuras acus (MacGregor, 1985, 57; Beal, sin fecha, 8, fig. 6). El procedimiento habitual para la realización de este tipo de manufacturas es el de realizarlas de una sola pieza, aunque también es posible encontrarlas realizadas con dos partes. En cuanto a los tipos de sierra que conocemos parece que en el trabajo del hueso se emplearon esencialmente dos tipos. Por un lado las sierras de hoja y por otro las sierras de hilo (Beal, 1983a, 23), además de las sierras de doble hoja que según MacGregor se podrían emplear en la realización de cortes de pequeño grosor (MacGregor, 1985, 55).

También relacionado con la preparación del hueso para su posterior trabajo resultaba una práctica bastante frecuente el humedecer la materia prima con el fin de que resultara más maleable y por tanto más fácil de trabajar. Según MacGregor los productos para ablandar la materia prima irían desde agua caliente hasta algunas sustancias ácidas como la leche agria o el vinagre (MacGregor, 1985, 63).

Además de estas herramientas, se debieron utilizar en las labores de talla y preparado cuchillos, tanto de sierra como sin ella, que servirían para desbastar e ir dando forma a las futuras acus, antes de terminarlas mediante el refinado o pulido de su superficie (MacGregor, 1985; (Johnson, 1972). Este procedimiento es en nuestro caso, claramente observable, tanto por las huellas apreciables en el trabajo de las cabezas como por las marcas longitudinales que se aprecian en los cuerpos de las mismas (Johnson, 1972, 139; MacGregor, 1985, 55).

Un ejemplo que nos permite constatar esta forma de fabricación lo constituyen las trazas de fabrica en las agujas de cabeza cónica y cuello rebajado del tipo $V$ de nuestra tipología (Lam IV. núm 80 a 83 ), en las que el estrechamiento de la parte superior del cuerpo se ha realizado mediante el desbastado de éste, dejando las huellas longitudinales a las que nos referíamos anteriormente.

Una vez obtenida la forma deseada se procedería a las labores de acabado (Viana, 1944, 400) que también resultan atestiguables, debido a la presencia de líneas transversales paralelas entre sí (MacGregor, 1985, 58), distribuidas a lo largo del cuerpo de la pieza que, curiosamente, tienden a presentar una inclinación con respecto al cuerpo de esta de más de $45^{\circ}$, hecho este que creemos puede deberse a la posición de la pieza con respecto al elemento abrasivo empleado en la terminación de la aguja, y no al revés, dadas las reducidas dimensiones de las piezas de las que este trabajo es objeto. 
Los elementos empleados para realizar esta tarea debieron ser variados, desde la hoja de un cuchillo que a nuestro juicio sería lo que produciría las marcas longitudinales sobre el cuerpo de la aguja (Johnson, 1972, 139), hasta algún elemento mineral del tipo piedra pómez o un simple papel de lija o arena que serviría para lijar la pieza y obtener un acabado fino (MacGregor 1985, 58), en algunos casos extremadamente refinado.

\section{TÉCNICAS DECORATIVAS}

Dentro de las labores de acabado deberemos hacer mención a las decoraciones que, aunque bastante escasas en nuestra colección, son una práctica habitual en la fabricación de acus crinales (MacGregor, 1985; Beal 1983a, Beal, 1984). Por un lado deberemos resaltar las figuradas, caso de nuestras piezas antropomorfas o zoomorfas, mientras que por otro lado las decoraciones incisas se presentan como las más características (aunque insistimos, en nuestro caso, son realmente escasas) sobre este tipo de manufacturas.

Pese a que a priori gran parte de las piezas objeto de este trabajo, y más especialmente las de cabeza esférica, semiesférica u ovales, ofrecían la impresión de estar elaboradas mediante torneado (MacGregor, 1985, 58; Beal 1983a, 30) -práctica habitual en el trabajo del hueso (enmangues, bisagras, etc...)-, la directa observación de éstas nos llevó a desechar esta posibilidad, ya que este tipo de acabado en las cabezas en ningún caso es el resultado del torneado sino más bien del tallado, hecho que provoca que en algunas ocasiones los acabados de estas sean ciertamente defectuosos.

Por último, haremos referencia a una serie de piezas que presentaban una coloración verdosa (Lám II. núm 24, 33, Lám III. núm 47, 55, Lám IV. núm 82) y que podían interpretarse en dos sentidos. Por un lado, la coloración de estas piezas podía deberse a haber estado en contacto con objetos de metal durante el período que permaneció sepultada. Por otro lado, podría haberse teñido, como ocurre con algunos ejemplares de Dover (MacGregor, 1985, 67) y de Conimbriga, cuya coloración parece deberse a un acción intencionada (Alarçao; Etienne; Moutinho y Ponte, 1979, 128), por lo que nos inclinamos a pensar que nuestras piezas deben su color a la actividad del artesano. El teñido de las piezas de hueso parece una práctica normal en época romana, por lo que podemos encontrar entre las manufacturas en hueso piezas teñidas de rojo, verde o alfileres, en este caso relacionados con la vestimenta, que presentan el cuerpo envuelto en un fina hoja de oro (MacGregor, 1985, 70). 
Sobre la técnica empleada para teñir de verde las manufacturas en hueso podemos retomar el testimonio de Plictho de Gioanventura Rosetti (1548), que afirmaba que el hueso puede teñirse de verde introduciéndolo en vinagre rojo junto con algunas monedas de cobre (MacGregor, 1985, 70). Este procedimiento lo hemos podido comprobar nosotros mismos, obteniendo resultados bastante parecidos a las coloraciones que presentan nuestras piezas.

Por último debemos indicar que algunos de los ejemplares de nuestra colección muestran signos claros de haberse partido en algún momento y de haberse reutilizado de nuevo mediante la obtención de una nueva punta (Lám III. núm 45), hecho este que por el momento, sólo lo habíamos constatado en el caso de las agujas de coser, y que a juzgar por lo visto también debió ser una práctica habitual sobre las acus crinales.

\section{TIPOLOGIA}

Antes de adentrarnos de lleno en cuestiones relacionadas con la tipología de las acus crinales, resultaría bastante interesante intentar establecer una terminología que nos permita definir cada una de sus partes de la manera más homogénea posible.

Pese a que la mayor parte de éstas son el resultado del trabajo de una única pieza de hueso y que las variantes tipológicas son bastante numerosas, morfológicamente podemos distinguir en ellas varias partes, a las que denominaremos "cabeza», "cuello", "cuerpo» y «punta».

La cabeza se corresponderá en términos generales con el «extremo proximal» o parte superior de la pieza, aquella en la que reside la variedad tipológica a la que antes haciamos alusión, además de ser la parte más definitoria de la pieza y que en términos generales es el criterio elegido por todos los autores para elaborar sus tipologías ?

Bajo la cabeza, se localiza el cuello de la pieza, que morfológicamente lo podríamos definir como el estrangulamiento o estrechamiento que sirve como elemento de transición entre el cuerpo y la cabeza o extremo proximal. Por lo general no suele ser un elemento morfológicamente definitorio, aunque en algunas piezas con cabezas zoomorfas o antropomorfas aparece ricamente desarrollado.

\footnotetext{
7 Hemos recurrido a las tipologías de BECKMANn para las agujas de bronce, a la de BEAL para los hallazgos de Nîmes y Lyon, AlaRÇAO y ÁvILA FranÇA para las excavaciones de Conimbriga y Crummy, MACGREgOR y STEVENSON para yacimientos de Inglaterra y Escocia.
} 
La siguiente parte que nos interesa definir es el cuerpo que se correspondería con la parte medial de la pieza. A priori no se presenta como un elemento morfológicamente definitorio, ya que por lo general se adapta a unos patrones morfológicos homogéneos definidos por la sección más o menos circular y por presentar un suave engrosamiento en la parte superior del mismo. Sin embargo, y en el caso de nuestra colección, nos dimos cuenta que en las piezas clasificadas dentro del tipo I, se producían dos hechos que morfológicamente las distinguían de las otras. Por un lado no tenían la cabeza desarrollada y carecían del engrosamiento en la parte superior del cuerpo, a la que antes hacíamos alusión, ya que el mayor diámetro de la pieza se localizaba en el extremo proximal, desde donde comenzaba a estrecharse hasta llegar a la punta.

Por último no nos queda más que referirnos a la punta o extremo distal que, en el caso de este tipo de manufacturas hemos preferido que no fuese objeto de ningún criterio clasificador, puesto que en el caso de las acus crinales carecía de relevancia funcional, además de que el numero de ejemplares de nuestra colección conservados íntegramente es bastante pequeño, siendo esta la parte que habitualmente se ha perdido en las piezas catalogadas.

Sin más, presentamos a continuación la tipología y el catálogo de las acus crinales de la ciudad hispanorromana de Complutum, realizado sobre un total de 142 piezas, procedentes de los diferentes yacimientos a los que al principio hacíamos referencia, atendiendo esta selección ante todo, a aquellas que en primer lugar estuviesen integras, y en segundo lugar a aquellas que fuesen totalmente reconocibles como las manufacturas que nos ocupan. Del total de las 142 piezas objeto del presente trabajo, tan sólo incluimos en el catálogo un total de 103 piezas, pues solamente estas presentaban elementos morfológicos (cabeza o extremo proximal) determinantes a la hora de incluirlos en alguna de las categorías tipológicas que a continuación estableceremos.

Tras el estudio detenido del total de nuestros alfileres para el cabello seleccionadas, hemos podido establecer una secuencia tipológica, basada en la morfología de la cabeza (extremo proximal) y el cuerpo (parte medial), clasificación que en las siguientes páginas pasamos a describir:

Tipo I (Lám. l)

Englobamos en esta categoría todas aquellas acus crinales en las que la característica morfológica principal es la ausencia de cabezas desarro- 

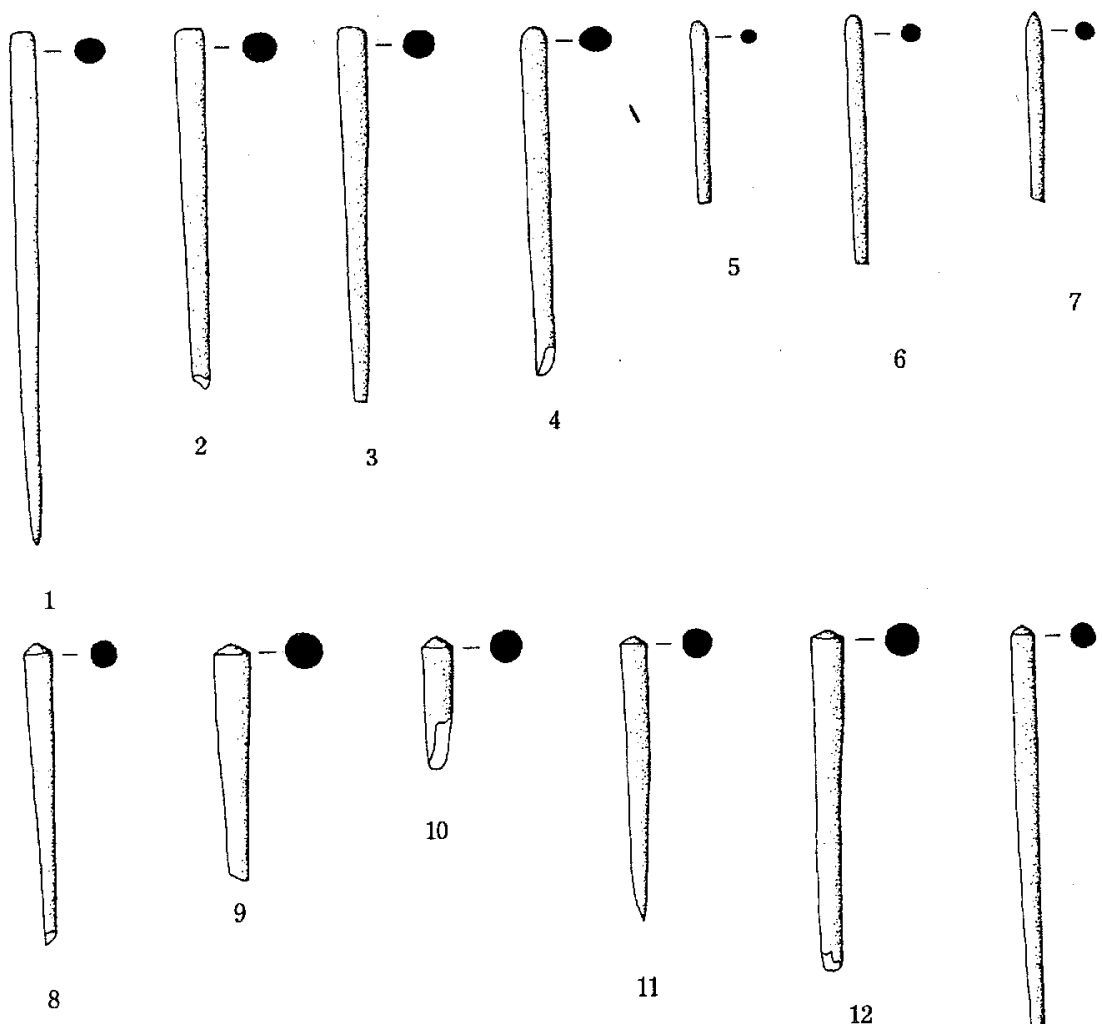

12

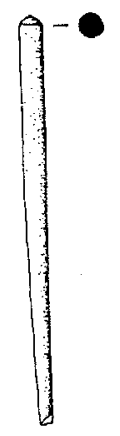

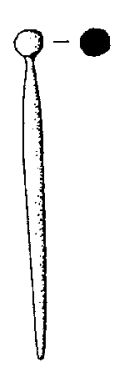

14

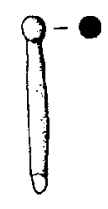

15

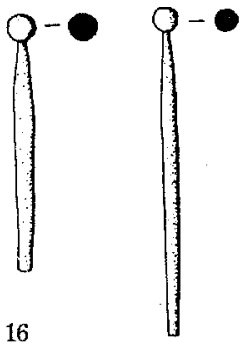

17

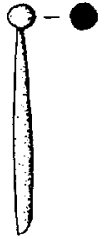

18

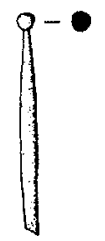

19

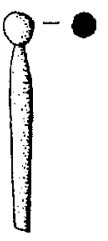

20

Fig. 1. Repertorio de acus crinalis de la ciudad hispanorromana de Complutum. Tipo I (1 a 13) y Tipo // (14 a 20). 
lladas y dentro de las cuales no existe ningún elemento diferenciador que nos permita clasificarla como un instrumento relacionado con el peinado, ya que las características del resto de las acus que hemos podido estudiar, como son la presencia de cabeza diferenciada y aparición en el cuerpo de un ligero engrosamiento - características cuya finalidad es el poder evitar que el acus pueda resbalar y deshacer el peinado creado- no se producen en este tipo. Dentro de este grupo distinguimos cuatro variantes establecidas en función de la forma en como se realiza la terminación o remate de la pieza en su extremo proximal o parte superior

Tipo la (núms. 1 al 3)

Caracterizado por presentar el extremo o vértice de forma llana, sección más o menos circular. Hemos encontrado paralelos de este tipo en Lyon (Beal, 1983a, 185), Nîmes (Beal, 1984, 49), en distintos yacimientos de Inglaterra y Escocia, así como un ejemplar realizado en bronce, documentado en las antiguas excavaciones de la ciudad de Conimbriga, clasificado por Elsa Ávila França $(1968,80)$ como de «cabeça indefinida». Este tipo se corresponde con el tipo XX, 2 de Beal (1983a, 184), con las denominadas "Headless Pins" de Mc Gregor $(1985,116)$ o las tipo 1 de la de Crummy $(1979,159)$.

En cuanto a las cronologías que ofrecen estos tipos parece que, de manera general y para los yacimientos a los que nos referíamos en la bibliografía, irían desde época de Claudio hasta la primera mitad del siglo IV.

Hemos podido documentar en nuestra colección un total de tres ejemplares de los que sólo uno se encuentra completo ( $n^{\circ} 1$ ), estando los demás fragmentados en la punta ( $n^{\circ} 2$ y 3). En cuanto a su datación, no existen contextos estratigráficos fiables, por lo que no nos es posible ofrecer ningún matiz a la cronología ya expiresada.

Tipo lb (núms. 4 al 6 )

Su extremo o vértice aparece rematado de forma circular, con las mismas características que su grupo presenta en el cuerpo. Sus paralelos tipológicos los encontramos en el tipo $X X, 4$ de Beal, según el cual nos hallamos ante un tipo ampliamente difundido y cuya cronología no resulta por el momento nada precisa. (Beal, 1983a, 187; Beal, 1984, $52)$. 
Hemos documentado tres ejemplos de este tipo pero ninguno íntegro. Tan sólo una de éstas (Lám I, núm. 5) ha podido ser fechada en un período comprendido entre el siglo iv y $\vee$ d.C.

Tipo Ic (núm. 7)

Definido por rematar en su extremo de forma ojival o apuntada y el cuerpo y sección dentro de los patrones morfológicos de su tipo.

Tipológicamente encajaría con el tipo XX, 4 de Beal (Beal, 1983a, 187; Beal, 1984, 52), dentro del que este autor también incluye nuestro tipo Ib, aunque también las podemos relacionar con las denominadas de «cabeça indefinida» (Ávila França, 1968, 80). En Complutum aparecen en contextos que van del siglo $\mathrm{IV}$ al $\vee$ d.C, al igual que el tipo anterior.Solo contamos con un ejemplar fragmentado y del que sólo conservamos la mitad superior.

Tipo Id (núms. 8 al 13)

Presenta su vértice rematado de forma cónica, siendo su cuerpo morfológicamente idéntico al de todos los ejemplares del tipo I.

Este tipo aparece incluido en la tipología de Mc Gregor como las "Headless Pins» (MacGregor, 1985, 116), Crummy las ubica en su tipo 1 (Crummy, 1979, 159), tipos ambos que también nos servían para buscar paralelos con nuestro tipo la, no obstante hemos optado por presentarlas de manera diferenciada de las Complutum la, pues creemos que constituyen dos grupos definidos por dos formas distintas de acabado en su cabeza.

Tipológicamente se corresponden con el tipo XX, 3 de Beal (1983a, 186), los de cabeza en forma de pirámide de Conimbriga (Alarçao; Etienne; Moutinho y Ponte, 1979, 129) o los «sem cabeça definida» que Ávila França publica en las antiguas excavaciones de la misma ciudad (Ávila França, 1979, 80).

Beal las sitúa a partir del siglo ॥ d.C. hasta la Grecia bizantina (Beal, $1984,51)$ hecho que, para el momento de origen, parece estar apoyado por los hallazgos de algunos de estos tipos en Conímbriga, documentados en una canalización de las termas de época trajanea (Alarçao; Etienne; Moutinho y Ponte, 1979, 129).

Por su parte Crummy $(1979,159)$ situaba el momento inicial para este tipo de acus en época Flavia, aunque los hallazgos de estos tipos en 
Chichester o Sussex, parecen demostrar su existencia en época de Claudio (MacGregor, 1985, 116). Por lo que se refiere a la fecha final para la realización de estos tipos, estos dos autores plantean que debe situarse en torno a la primera mitad del siglo III.

Hemos podido documentar un total de seis piezas que se corresponden con este tipo y que situamos cronológicamente desde la segunda mitad del siglo I d.C al siglo v d.C., apareciendo todas fragmentadas en su punta salvo la núm. 11, que es la única que conservamos íntegra.

Tipo II (Láms. I, II y III)

Morfológicamente se caracteriza por presentar la cabeza diferenciada en forma de esfera, trabajada de forma más o menos regular. Atendiendo a la forma de la cabeza podemos distinguir dos subtipos o variantes definidos por la terminación de la esfera en su parte inferior - donde se une con el cuello-, ya que esta podrá realizarse de forma plana y en cuyo caso la incluiremos en nuestro tipo Ilb y aquellas en las que estas particularidades formales no se dan, no estando tan marcada la transición cabeza-cuerpo y que llamaremos tipo lla.

Este tipo, como en la mayor parte de las piezas que presentan la cabeza desarrollada, posee un ligero engrosamiento en la parte superior del cuerpo, que probablemente responda a criterios estrictamente funcionales, como pueden ser los de evitar que el acus resbale entre los cabellos, tal y como indicábamos anteriormente. Además este hecho nos permitió llegar a determinar que los fragmentos de cuerpo sin este tipo de engrosamiento, posiblemente podrían pertenecer a otros tipos de manufacturas como las agujas de coser o simplemente el extremo de otros objetos como las ligulae o los stila.

En nuestro caso se trata de uno de los tipos más representados y que además cuentan con una gran difusión en los yacimientos más importantes. El hecho de que en la bibliografía no se plantee esta distinción tipológica nos lleva a abordar las cuestiones referentes a la distribución y a la cronología de estos tipos de manera previa a la definición de cada uno de nuestros subtipos.

De este modo nuestro tipo II (tanto el subtipo a, como el b), corresponde con el XX, 7 de J.C Beal documentado tanto en Lyon como en Nîmes (Beal, 1983a, 193; Beal, 1984, 52), con las denominadas «Spherical-Headed Pins» de MacGregor (MacGregor, 1985, 117), con las «Pins with simple ball heads» de Stevenson (Stevenson, 1955, 286), con 


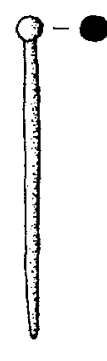

21

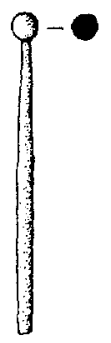

28

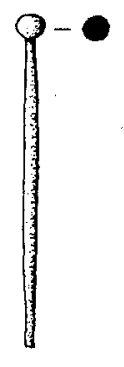

22

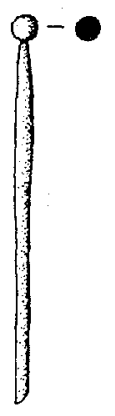

23

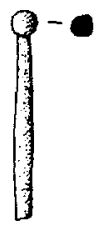

24

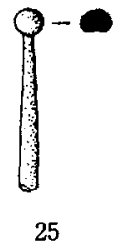

25

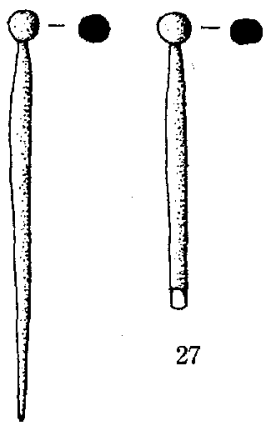

26
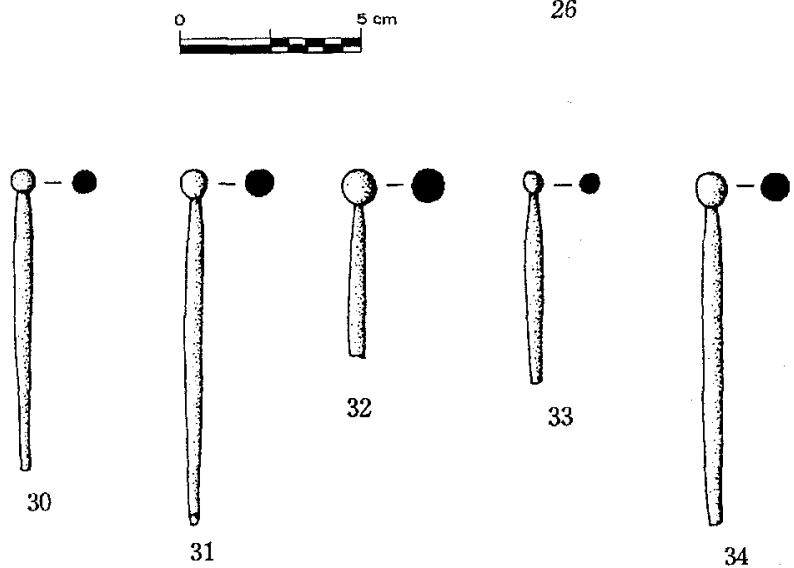

34
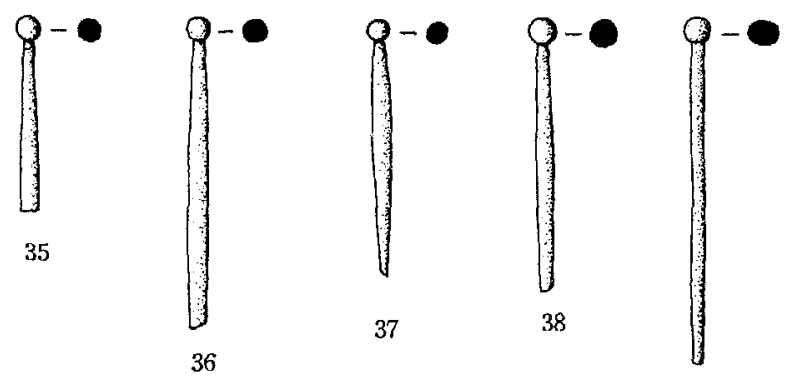

39
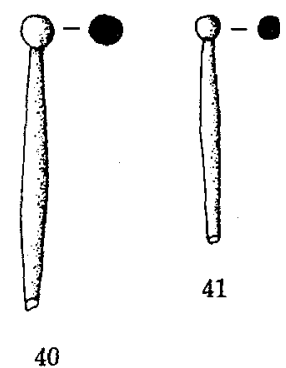

Fig. 2. Repertorio de acus crinalis de la ciudad hispanorromana de Complutum. Tipo II (21 a 41). 
las «Pins with spherical or ovoid head» de Crummy (Crummy, 1979, 161), con las del tipo 48 de la ya clásica, clasificación de Beckmann (Beckmann, 1966) de acus metálicas, con las definidas como de «cabeça sferoidal» de las antiguas excavaciones en Conimbriga (Ávila França, 1968, 75) y las de «tête sphérique» publicadas por Alarçao y su equipo (Alarçao, Etienne, Moutinho y Ponte, 1979, 128).

En términos generales podemos decir que la mayoría de los autores parecen ponerse de acuerdo en que se trata de uno de los tipos más difundidos, tanto cronológica como geográficamente. Así la fecha planteada iría desde el siglo I d.C, hasta el siglo IV o principios del v d.C. Tal debió ser la difusión de estas piezas que en algunos casos se plantean cronologías que se escapan del período que nos ocupa (siglos vIII al $x$ en algunos yacimientos de Inglaterra y Escocia) (MacGregor, 1985). De cualquier manera uno de los hechos que parecen claros es el origen romano de estas manufacturas (Stevenson, 1955).

Por nuestra parte diremos que, en el caso de los ejemplares procedentes de Complutum, la cronología para nuestros dos tipos (Ila y Ilb) se corresponde con lo aportada por los yacimientos consultados, aunque si analizamos este dato de manera más detenida, podemos observar que las piezas correspondientes al tipo lla son ligeramente más antiguas, ya que las hemos documentado en la primera mitad del siglo I d.C, mientras que el tipo Ilb lo hemos fechado a partir de la segunda mitad del siglo.

Tipo lla (núms. 14 a 45)

Morfológicamente se caracterizan por presentar la cabeza desarrollada en forma de esfera, el cuerpo de sección circular con un ligero engrosamiento en la parte superior del mismo. Los acabados de estas piezas resultan irregulares, tanto en las cabezas como en el resto de las piezas.

En la ciudad de Complutum hemos podido documentar 31 ejemplares de los que tan sólo conservamos cuatro completos ( $n^{\circ} 14,21,26$ y 45). Este último, el no 45 , corresponde con una pieza que ha sido reafilada. El resto de los alfileres aparecen fragmentados mayoritariamente en la punta.

Curiosamente encontramos entre estas, algunas piezas en las que la cabeza y en algunas ocasiones el cuerpo ha sido seccionado de manera longitudinal (no 20 y 24), hecho al que no encontramos ninguna explicación de no ser que fuese algún "arreglo» al que se sometiese la pieza como consecuencia de su utilización en una función u otra, que desgraciadamente desconocemos. 
Por último también contamos con dos de estas piezas que presentan coloración verdosa ( $\mathrm{n}^{\mathrm{O}} 33$ y 24), lo que probablemente sea por haberlas sometido a algún proceso de teñido (MacGregor, 1985, 70; Alarçao, Etienne, Moutinho y Ponte, 1979, 126).

Tipo Ilb (núms. 46 a 59)

Esta variante participa de las mismas características que el tipo Complutum Ila, con la particularidad de presentar la base de la esfera que constituye la cabeza de la pieza muy marcada lo que acentúa la transición entre ésta y el cuerpo. Este rasgo pensamos se debe a cuestiones de fabricación.

De cualquier manera, esta particularidad formal también es resaltada por J. C. Beal en el catálogo de las piezas provenientes de la ciudad de Nîmes (Beal, 1984, 52), aunque en este caso no se ha considerado un tipo aparte.

Contamos en Complutum, con 14 ejemplares que se adaptan a este patrón morfológico. De ellos tan sólo dos aparecen íntegros (no 46 y 58), mientras que los demás aparecen fragmentados en el cuerpo y la punta indistintamente. De ellos sólo uno presenta la cabeza seccionada longitudinalmente ( $\left.n^{\circ} 55\right)$ como ocurría en el caso del grupo anterior, además de presentar coloración verdosa. Hecho este que se da en dos piezas de este tipo (no 47 y 55 ).

Tipo III (Láms. III y IV; núms. 60 a 77)

Se trata de un tipo que, al igual que el anterior, se encuentra ampliamente representado entre los ejemplares procedentes de la ciudad de Complutum. Está bastante difundido, ya que resulta relativamente frecuente en Nîmes (Beal, 1984), Lyon (Beal, 1983a) y Conimbriga (Alarçao; Etienne; Moutinho y Ponte, 1979; Ávila França, 1968).

Morfológicamente se caracteriza por presentar la cabeza desarrollada de forma ovalada y sección más o menos circular en el cuerpo y la cabeza. Característico de esta aguja es también el engrosamiento en la parte superior de cuerpo.

Se corresponde este tipo, con el XX, 8 de J.C. Beal («tête en forme d’olive») (Beal, 1983a, 193) y con las que Ávila França denomina de "cabeça oval» (Ávila França, 1968, 77). Por su parte tanto Crummy como 


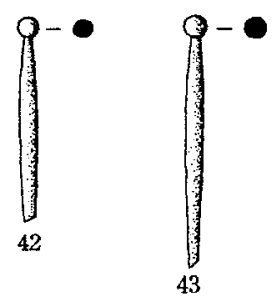

o
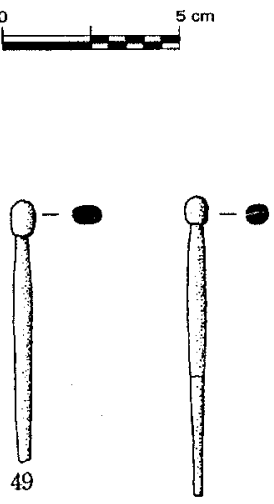

50
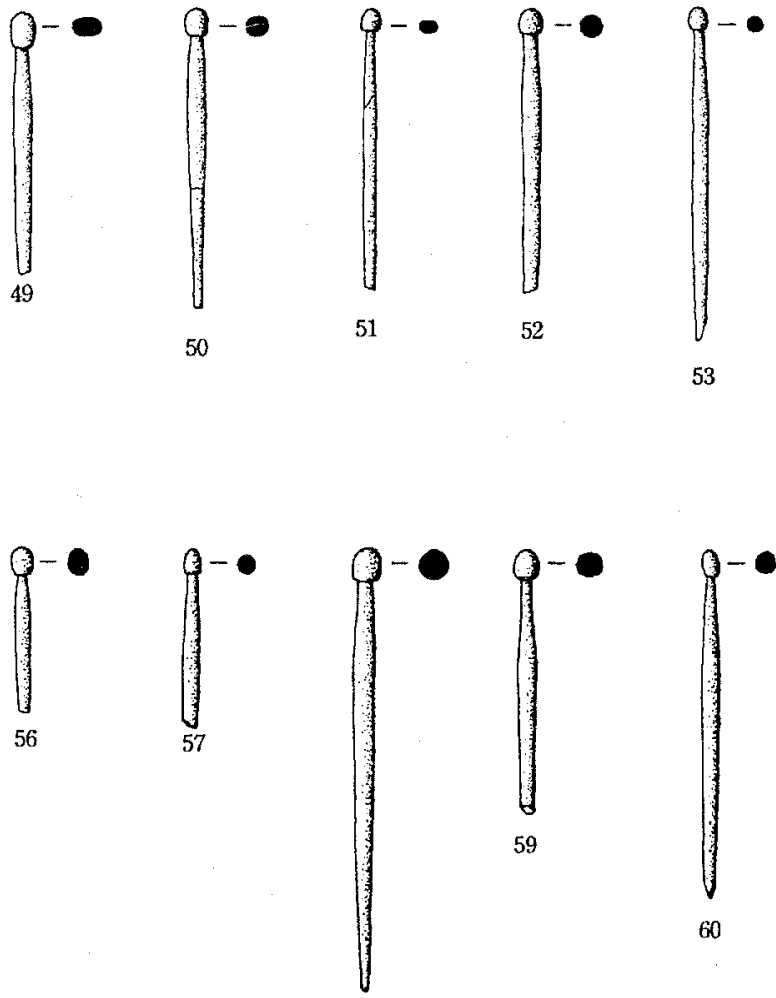

53
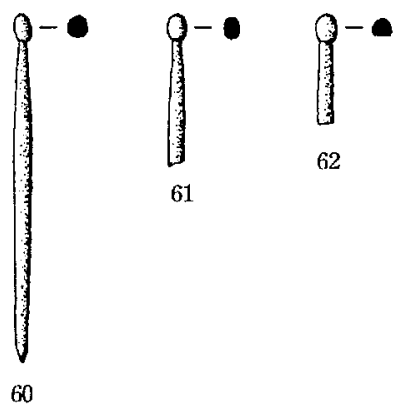

58
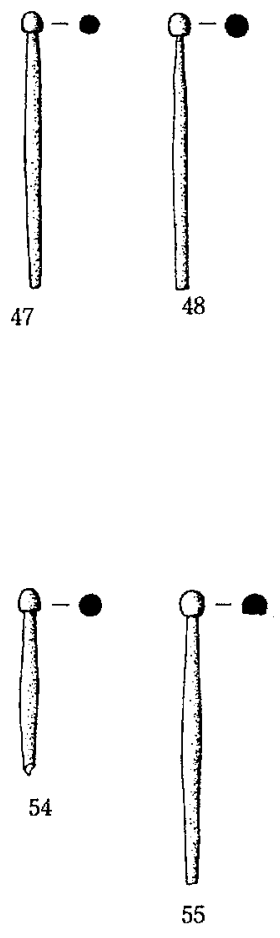

55

Fig. 3. Repertorio de acus crinalis de la ciudad hispanorromana de Complutum. Tipo II (42 a 59) y Tipo III (60 a 627). 

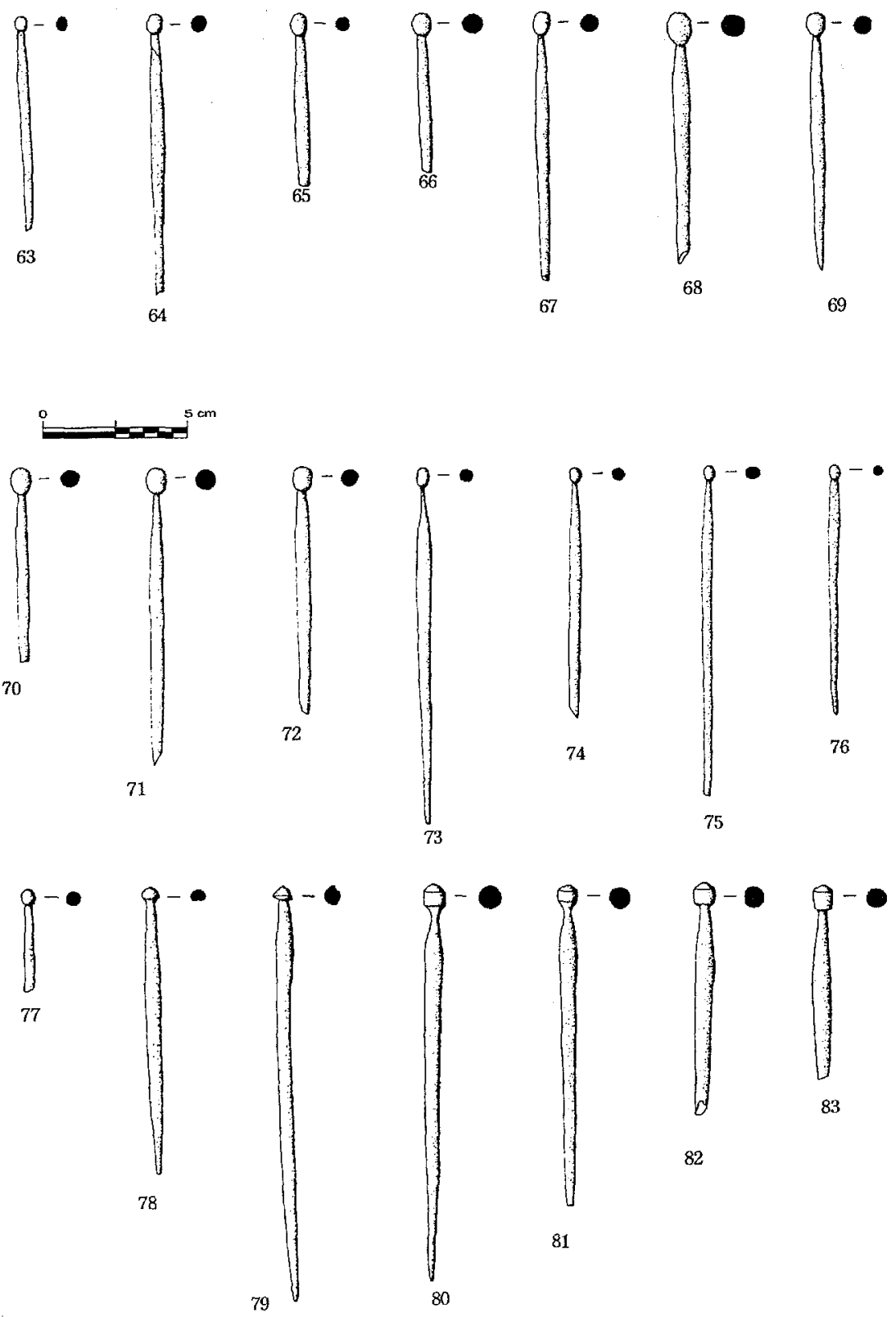

82

Fig. 4. Repertorio de acus crinalis de la ciudad hispanorromana de Complutum. Tipo III (63 a 77); Tipo IV (78 y 79) y Tipo V (80 a 83). 
MacGregor incluirian este tipo dentro de las "Pins with spherical or ovoid head» O las «spherical-Headed Pins» (MacGregor, 1985, 117 y Crummy, $1969,161)$ de los que hablábamos al referirnos a nuestro tipo II.

Es un tipo ampliamente difundido que iría desde el siglo I d.C hasta el siglo $V$ d.C. Ávila França recoge un ejemplar de este tipo procedente del Tosal de Manises (Ávila França, 1968, 77) en un contexto del siglo I d.C. Quizás el único aspecto que podamos aportar con el fin de matizar la cronología ya expuesta sea el hecho de que las piezas de Complutum están fechadas a partir de la segunda mitad del siglo । d.C.

Contamos con 18 piezas de las cuales 5 se han conservado completas (no 60,71, 73 y 76). Las demás se encuentran fragmentadas indistintamente en el cuerpo o en la punta.

Al igual que ocurría en la piezas del tipo II, también hemos podido documentar una acus en la que la cabeza había sido cortada longitudinalmente $\left(n^{\circ}\right.$ 62).

Tipo IV (Lám. IV; núm 78 y 79)

Se trata de un tipo bastante menos representado que los que hemos visto por el momento, además de estar menos difundido que los otros ya que sólo lo encontramos representado en Conimbriga.

Morfológicamente se caracteriza por tener la cabeza desarrollada de forma semiesférica, sección más o menos circular y el cuerpo adaptado a los patrones tipológicos de los que venimos hablando desde las agujas del tipo II.

Tipológicamente podrían formar parte de las descritas como de "cabeça parabolica» de Ávila França (Ávila França, 1968, 77) las de "tête parabolique" de la ciudad de Conimbriga (Alarçao, Etienne, Moutinho y Ponte, 1979, 27). No obstante no se trata de un grupo que tipológicamente encaje de manera completa con las piezas incluidas en estas tipologías. Quizás el tipo que mejor se adapte a nuestras piezas es la forma 50 de Beckmann (1966). Este investigador, fecha las piezas en bronce, correspondientes a esta forma, a partir de la primera mitad del siglo I d.C y se prolongarán en el tiempo, según Alarçao, hasta el siglo III d.C., aunque en Complutum podemos retrotraer esta cronología hasta el siglo $\mathrm{V}$ d.C.

En Alcalá de Henares hemos contabilizado sólo dos piezas realizadas en hueso pertenecientes a este tipo de las que ninguna se conserva ínte- 
gramente ya que una aparece sin punta ( $\left.n^{\circ} 78\right)$ y la otra presenta la cabeza parcialmente fragmentada ( $\left.\mathrm{n}^{\circ} 79\right)$.

Además de estas dos piezas, tenemos una tercera realizada en bronce y que por motivos evidentes no incluimos en nuestro catálogo.

Tipo V (Lám. IV; núm 80 al 83)

En este caso, nos hallamos ante un tipo que por el momento sólo está representado en Complutum y que, tanto formal como técnicamente, parece derivado de la forma Id, ya que da la sensación de ser una de estas piezas a las que con el objeto de conseguir una cabeza desarrollada, se les ha rebajado el cuello, a juzgar por las huellas de fabricación, siempre con posterioridad al primer acabado de la pieza.

Se trata, por tanto, de piezas con la cabeza desarrollada en forma de pirámide sobre cuerpo cilíndrico. En estas, la transición entre la cabeza y el cuerpo, está muy acentuada (probablemente por estar realizada después del acabado original de la pieza).

Este tipo esta representado por cuatro piezas de las que sólo conservamos una en estado integro ( $n^{\circ} 80$ ). Además contamos con una de estas piezas de color verdoso ( $n^{\circ} 82$ ). En cuanto a la cronología, hemos podido documentarlas desde el último cuarto del siglo I d.C. (más concretamente en un momento no anterior en ningún caso al año 80 d.C.), hasta el siglo v d.C.

Tipo VI (Lám. V; núms. 84 y 85)

Se trata de un tipo bien representado en yacimientos como Conimbriga, Nîmes, Lyon u otros yacimientos Ingleses y Escoceses, así como también en Italia y en Grecia (Beal, 1983a; Beal, 1984; MacGregor, 1985; Ávila França, 1968; Alarçao, Etienne, Moutinho y Ponte, 1979), aunque en Complutum sólo poseemos dos ejemplares.

Morfológicamente nos encontramos ante una pieza caracterizada por presentar la cabeza desarrollada en forma lenticular o bicónica, sección circular y cuerpo con el engrosamiento característico en la parte superior del cuerpo.

Tipológicamente las podemos relacionar con las del tipo XX,5 de J.C. Beal (Beal, 1983a, 187), las "Nail-Headed Pins» de MacGregor (MacGregor, 1985,117 ), las piezas del grupo VI b de Beckmann (Beckmann, 1966) o las de «cabeça biconica» de Conimbriga (Ávila França, 1968, 71). 


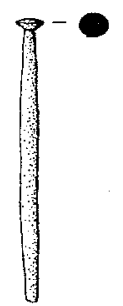

84
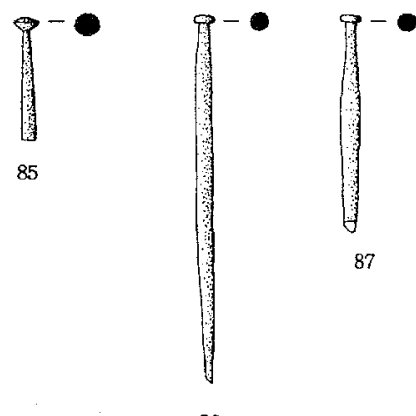

86
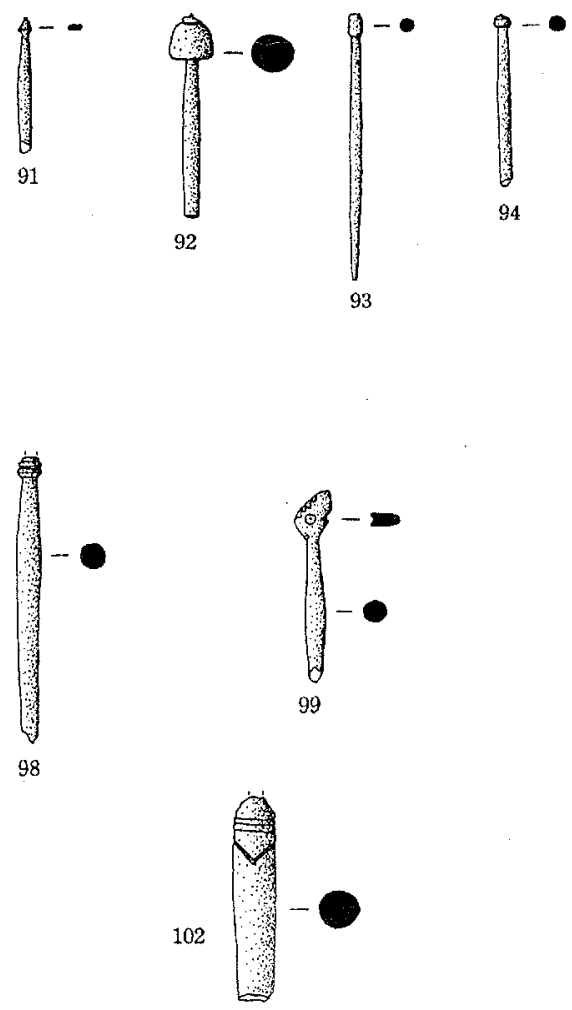
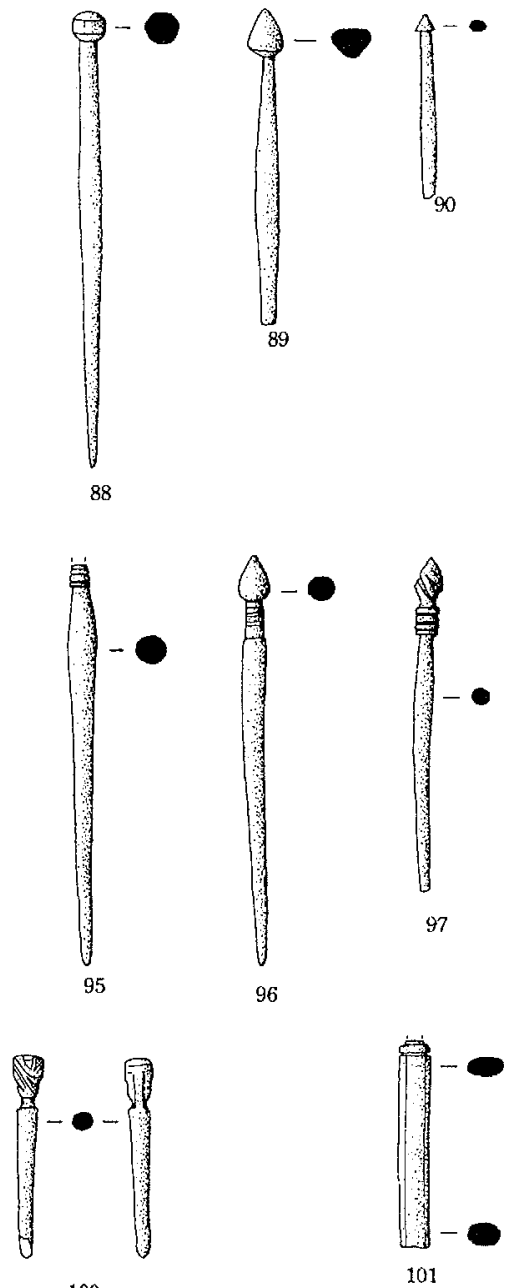

100
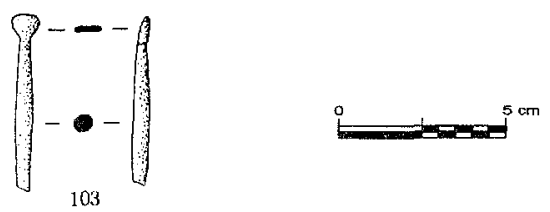

Fig. 5. Repertorio de acus crinalis de la ciudad hispanorromana de Complutum. Tipo VI (84 y 85); Tipo VII (86 y 87); Tipo VIII (88); Tipo IX (89 a 91); Tipo X (92); Tipo XI (93); Tipo XII (94); Tipo XIII (95-98); tipo XIV (99). Tipo XV (100); Atribución formal indeterminada $(101,102)$ y Ligula (103). 
Por su parte Alarçao (Alarçao; Etienne; Moutinho y Ponte, 1979) y Ávila França distinguen varios subtipos, puesto que se trata de uno de los tipos mas difundidos en Conimbriga. Por un lado las cabezas bicónicas, categoría a las que pertenecerían nuestras piezas, de conos desiguales y las que presentan un anillo entre los conos.

Cronológicamente, siguiendo a Beckmann (Beckmann, 1966), las podemos ubicar desde el siglo I d.C hasta el siglo $\mathrm{iv}$ d.C, aunque en Conimbriga en la calle Norte del foro las tenemos en contextos del siglo $\mathrm{V}$ d.C. (Alarçao; Etienne; Moutinho y Ponte, 1979, 127). For otro lado en Britania no encontramos estos tipos antes del siglo III d.C.(MacGregor, 1985 Y Crummy, 1979).

De cualquier manera esta cronología (del । al v) parece cumplirse en todos los yacimientos consultados. En nuestro caso la datación de las piezas de este tipo se adaptaría perfectamente al período comprendido entre la segunda mitad del siglo i y el $v$ d.C., habiendo podido documentar tan sólo dos de estas piezas, que desgraciadamente se encuentran fragmentadas en la punta ( $n^{\circ} 84$ ) y en el cuerpo ( $\left.n^{\circ} 85\right)$.

Tipo VII (Lám. V; núms. 86 y 87)

Morfológicamente lo podemos definir como un tipo caracterizado por presentar la cabeza desarrollada en forma discoidal, sección más o menos circular y cuerpo con engrosamiento en la parte superior del cuerpo.

Tipológicamente se incluyen en el mismo grupo que MacGregor incluía las del tipo VI (Nail-headed pins) (MacGregor, 1985, 117), dentro del grupo que Ávila França denomina de «cabeça discoide» (Ávila França, 1968, 71), o el tipo no 95 de Beckmann (Beckmann, 1966, XXIII, t. 2, fig. 95).

Según Beckmann, la cronología para las piezas de este tipo realizadas en bronce, sería del I d.C. hasta el II d.C., aunque en yacimientos como Strasbourg encontramos estas formas en contextos del siglo IV d.C. En Complutum tenemos tan sólo dos ejemplares que se conservan fragmentados en la punta ( $n^{\circ} 86$ y 87 ), de los que no podemos establecer ninguna precisión cronológica.

Tipo VIII (Lám V; núm. 88)

Se caracteriza este tipo, por presentar la cabeza desarrollada de forma poligonal y cuerpo de sección circular con engrosamiento en su parte superior. 
Tipológicamente se emparentaría con las que en al ciudad de Conimbriga se definen como de cabeza de diamante o poliedro (Alarçao; Etienne; Moutinho y Ponte, 1979, 127), terminología similar a la empleada en la ciudad de Conimbriga (Ávila França, 1968, 75).

La cronología para este tipo no resulta nada clara, por eso sólo podemos decir que en la ciudad de Conimbriga se han documentado en contextos ubicados en época de Trajano y en los niveles de la destrucción del foro (Alarçao; Etienne; Moutinho y Ponte, 1979). Por su parte, en la llamada "Casa de los Cupidos» (Complutum), se documentó un ejemplar de este tipo cuya datación no era posterior al siglo v d.C. (Fernández-Galiano, 1984, 166). En Alcalá de Henares sólo tenemos un ejemplo de este tipo (no 88) que se conserva íntegramente.

Tipo IX (Lám. V; núms. 89 a 91)

Morfológicamente la podemos definir como un tipo que se caracteriza por tener la cabeza desarrollada de forma triangular o apuntada, con distintas secciones (circular, oval o incluso triangular) y cuerpo con el característico engrosamiento en su parte superior que al contrario de la cabeza, presenta sección circular.

Tipológicamente podríamos equipararlo con la de "cabeça de dardo» de Ávila França $(1968,75)$ o las de «à chaveux en forme de dard» de las recientes excavaciones de la ciudad de Conimbriga (Alarçao; Etienne; Moutinho y Ponte, 1979, 128).

Las apreciaciones cronológicas que podemos ofrecer no son demasiado clarificadoras, ya que se basan en el hallazgo de una de estas piezas en la necrópolis de Troia (Setúbal) en un contexto del siglo I d.C. Por otro lado también se han documentado piezas de Conimbriga en la canalización de las termas de época de Trajano y en el momento de destrucción de la «insula del vaso fálico» (Alarçao; Etienne; Delgado; Mayet y Moutinho, 1979).

Por lo que se refiere a los ejemplares Complutenses diremos que se reducen a tres que presentan características morfológicas algo distintas entre sí, distintas secciones en la cabeza, diferentes tamaños, siendo la mayor la $n^{\circ} 89$. Las fechas en las que hemos podido encuadrar nuestras piezas van desde la segunda mitad del siglo I d.C. hasta principios del siglo II d.C. 
Tipo X (Lám. V; núm. 92)

Se distingue este tipo por presentar la cabeza desarrollada de forma parabólica y la transición entre esta y el cuerpo se caracteriza por presentar un acentuado rebaje, que delimita muy bien ambas partes.

Hemos encontrado paralelos tipológicos en las clasificaciones de Ávila França (1968, 76-77), con la denominación «de cabeça parabólica», así como en los trabajos de Alarçao que las denomina de la misma forma (Alarçao; Etienne; Moutinho y Ponte, 1979, 128). En la tipología de Beckmann se correspondería con el no 50 (Beckmann, 1966).

Este investigador ubica cronológicamente las piezas de bronce, correspondientes a este tipo, dentro de la primera mitad del siglo । d.C., mientras que en Conimbriga la encontramos desde el I al III d.C. y según parece se trata de un tipo ampliamente difundido en Britania (Alarçao; Etienne; Moutinho y Ponte, 1979). En la ciudad de Complutum podemos fechar este tipo entre siglos iv al $\vee$ d.C.

Sólo hemos podido documentar un ejemplar que pertenezca a este tipo (no 92) y que además es una de las pocas piezas que presenta la cabeza decorada con una incisión en la parte superior de la misma. Se caracteriza por no presentar en el cuerpo el engrosamiento habitual en estas manufacturas.

Tipo XI (Lám. V; núm. 93)

El distintivo principal de este tipo es el de ofrecer cabeza cilíndrica, la cual aparece rebajada tanto en su parte superior como inferior, pudiéndose observar perfectamente como la transición entre esta y el cuerpo aparece ligeramente resaltada.

Contamos con paralelos tipológicos en los estudios de Beal, quien las llega a denominar como acus de «boule allongée» (Beal, 1983a, 201) que se corresponden con el tipo XX, 12, mientras que para Ávila França constituyen el tipo de "cabeça barrilóide" (Ávila França, 1968, 78).

Cronológicamente no contamos con ninguna especificación en las diferentes obras publicadas que haga referencia a esta cuestión. Sin embargo en el caso de Complutum se ha podido establecer una cronología entre los siglos $\vee \vee$ y $\vee$ d.C., para el único ejemplo con el que contamos de este tipo ( $n$-93), por lo que, teniendo en cuenta los pocos paralelos que hemos podido encontrar, podemos llegar a determinar que esta forma no 
tuvo mucha difusión, haciendo su aparición de forma esporádica en nuestro yacimiento.

Tipo XII (Lám. V; núm. 94)

Se trata de un tipo escasamente representado del que tan sólo hemos encontrado paralelos en Lyon (Beal, 1983a, 188) y Conimbriga (Alarçao, Etienne, Moutinho y Ponte, 1979).

Morfológicamente se caracteriza por presentar cabeza desarrollada en forma de prisma y cuerpo de sección circular con engrosamiento en su parte superior.

Desde el punto de vista tipológico, lo podríamos paralelizar con el tipo XX, 6 de Beal (Beal, 1983a) o de "tête en forme de prisme" de Conimbriga (Alarçao, Etienne, Moutinho y Ponte, 1979).

Cronológicamente son pocos los datos que podemos ofrecer, debido a que son muy escasos los ejemplares registrados de este tipo, que Beal sitúa desde finales del siglo I d.C. a principios del II d.C. (Beal, 1983a, 189), aunque en Conímbriga se ha documentado en contextos del siglo $\mathrm{V}$ d.C. (Alarçao, Etienne, Moutinho y Ponte, 1979). En Complutum, el ejemplar que se ha documentado, presenta una cronología bastante tardía comprendida entre los siglos IV y $\vee$ d.C. Nosotros contamos con un único ejemplar ( $n^{\circ}$ 94) que esta fragmentado en la punta y que aunque a priori da la sensación de ser el mismo tipo que el V, la diferencia esta en la forma en la que se ha obtenido la cabeza, además las dimensiones de esta pieza son mucho menores.

Tipo XIII (Lám. V; núms. 95 al 98)

Desde el punto de vista formal se caracteriza por presentar la cabeza desarrollada en forma huso o fusiforme. Presenta este tipo, un rasgo que hasta el momento no habíamos visto en otros ejemplares, que es el hecho de tener el cuello desarrollado a base de molduras en forma de toros y escocias. El cuerpo tiende a ser de sección circular con un ligero engrosamiento en su parte superior.

Tipológicamente se correspondería con el tipo XXI, 21 de Beal (Beal, 1983a, 224; Beal, 1984, 58) o las que Ávila França denomina de «cabeça cordiforme assente em toros» (Ávila França, 1968, 81).

Cronológicamente, Beckmann sitúa este tipo dentro de los siglos I y $\|$ d.C. (Beckmann, 1966), mientras que en yacimientos ingleses se datan 
entre los siglos III y IV d.C. En Nimes, han sido fechadas a partir del siglo I d.C. (Beal, 1984, 59).

En Complutum contamos con varios ejemplos de este tipo que presentan particularidades morfológicas diferentes, al mismo tiempo que los estados de conservación son variados, así sólo dos de los cuatro ejemplos conservan la cabeza ( $n^{\circ} 96$ y 97), mientras que los otros ( $n^{\circ} 95$ y 98) corresponden a fragmentos de cuerpo que conservan el cuello, razón por la que se las ha incluido en el catálogo.

Además una de las piezas ( $n^{\circ}$ 97) presenta la cabeza decorada mediante la técnica de la incisión, describiendo motivos oblicuos sobre el huso, al contrario que la otra pieza, que conserva la cabeza ( $\left.n^{\circ} 96\right)$, que presenta lisa la superficie del huso.

Cronológicamente los cuatro ejemplares correspondientes a este tipo se encuadran entre finales del siglo III d.C. y principios del siglo iv d.C. En la ciudad de Complutum ya pudimos atestiguar la presencia de este tipo de acus en la denominada "Casa de Leda» (Fernández-Galiano, 1984, 287), donde se documentaron dos ejemplares, uno de hueso y otro de metal (Fernández-Galiano, 1984, 231), que ofrecen una cronología que se encuadra dentro del siglo iv d.C. (Fernández-Galiano, 1984), así como otro ejemplo en el foro de Complutum donde se halló otra aguja que se corresponde con este tipo, y más concretamente con la $n^{\circ} 97$ de nuestra tipología, y que nos ofrece una cronología que abarca desde mediados del siglo I d.C. al siglo Iv d.C.

Tipo XIV (Lám V; núm. 99)

Se trata de uno de los tipo más interesantes puesto que presentan la cabeza zoomorfa, sin desarrollar el cuello de la pieza como elemento de transición entre la cabeza y el cuerpo que se adapta a los parámetros morfológicos que venimos describiendo. Por contra en este caso la cabeza presenta sección plana.

Tipológicamente la podríamos relacionar con las del tipo XXI, 11 de Beal (Beal, 1984) o tipos similares.

En cuanto a las cronologías para estas piezas figuradas, se plantea el siglo IV d.C., debido al establecimiento de paralelos con otros yacimientos de la Galia, pero en nuestro caso, el ejemplar con el que contamos de este tipo nos ofrece una cronología ubicada dentro de la segunda mitad del siglo I d.C. 
En el caso de nuestro alfiler, del que hemos perdido la parte inferior del cuerpo, desconocemos a qué tipo de animal puede corresponder la cabeza. De cualquier manera los paralelos decorativos resultan bastante cercanos con las piezas que presenta Beal (incisiones y círculos concéntricos) (Beal, 1984).

Tipo XV (Lám V; núm. 100)

Único ejemplo recogido en Complutum de aguja para el peinado con cabeza desarrollada con una figura humana, que desgraciadamente no hemos podido recuperar completa, sino que sólo conservamos la parte inferior del busto de un personaje ataviado con manto, que seguramente represente a una mujer, debido por un lado, a que los numerosos paralelos que hemos encontrado de este tipo de agujas antropomorfas siempre aparecen representando a mujeres con tocados o peinados muy elaborados y por otro, a que estamos ante un tipo de manufactura característico del mundus muliebris.

Tipológicamente es relacionable con los «alfiletes de cabeça figurativa» (Ávila França, 1968, 83) o con los «anthropomorphic pins» de MacGregor (MacGregor, 1985, 118).

Por lo que se refiere a la cronología de este tipo de piezas, parece que un elemento determinante a la hora de ubicarlo en el tiempo es el peinado de las figuras. En nuestro caso al carecer de la cabeza del busto debemos atender a criterios puramente estratigráficos para determinar la cronología de esta pieza, que se enmarca dentro de la segunda mitad del siglo I d.C.

Por último y ya para finalizar con la tipología de las acus crinales de la ciudad hispanorromana de Complutum nos gustaría referirnos a tres piezas ( $\mathrm{n}^{\circ} 101,102$ y 103) que presentaban algunas dudas en cuanto a su funcionalidad, bien por su forma, bien por el estado de conservación.

Las dos primeras ( $n^{0} 101$ y 102) resultarían ser fragmentos de la parte superior del cuerpo y cuello de acus que seguramente, a juzgar por algunas piezas de los museos de Lyon y Nîmes (Beal, 1983a; Beal, 1984), estuvieran figuradas.

Tipológicamente podríamos incluirlas en tipos como el XX, 15 de J.C. de Beal (Beal, 1983a), pero al carecer de la pieza completa en la parte superior y con el objeto de no establecer un tipo ajustándonos a unos criterios diferentes a los que han articulado nuestra tipología, preferimos abstenernos de incluirlas por el momento dentro de ninguna categoría. Ambos ejemplos presentan decoración, el primero ( $n^{\circ}$ 101) en la articulación del 


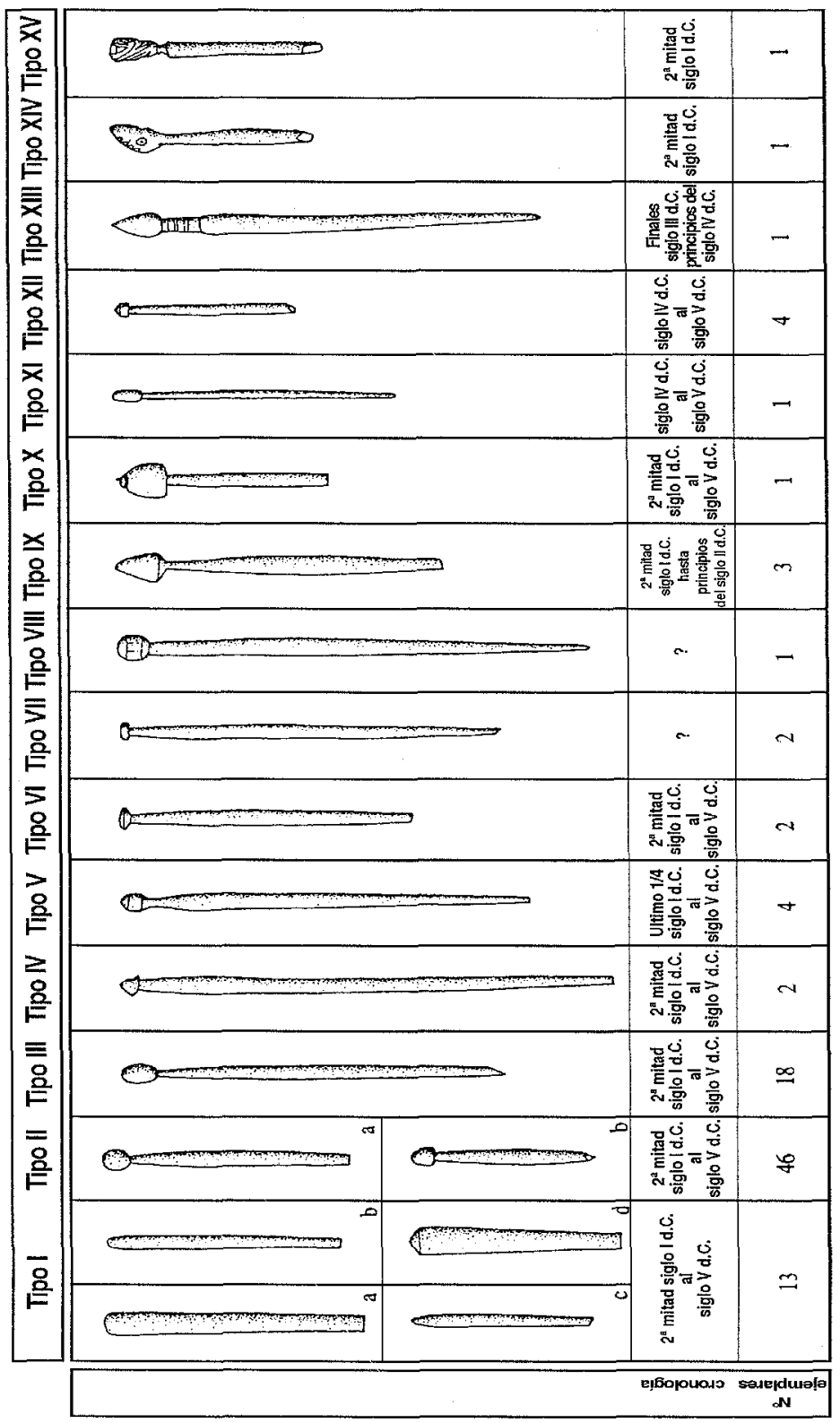

Fig. 6. Cuadro tipológico de las acus crinales de la ciudad hispanorromana de Complutum. 
cuello como veíamos en tipos anteriores y la otra ( $n^{\circ}$ 102) con decoración incisa a base de motivos lineales y de zig-zag alrededor del cuello de la pieza.

Por su parte la pieza $n^{\circ} 103$ presenta otra problemática distinta ya que pese a que algunos autores la incluyan en sus tipologías como un acus (MacGregor, 1985, 119), pensamos que dada su morfología debe más bien tratarse de una especie de ligula o aplicador de ungüentos o cosméticos tal y como reconocen Alarçao et Alii en Conimbriga, o como algún tipo de sonda para limpiar los oídos (BOROBIA, 1988; BEÁL, 1983a, 241; Alarçao; Etienne; Moutinho y Ponte, 1979, 183), de los que tenemos bien documentados en bronce.

De cualquier manera tipológicamente corresponderían con los «small disc-headed pins" (MacGregor, 1985, 119) que presentan el disco menos inclinado que nuestra pieza, por lo general alineado con el cuerpo de la pieza, o el tipo XXIII de Beal (Beal, 1983a, 241).

Cronológicamente, MacGregor las sitúa en contextos tardíos. Por su parte en la ciudad de Conimbriga encontramos un ejemplo de es tipo de pieza en bronce del siglo $\mathrm{v}$ d.C, aunque como atestiguan algunos ejemplos de estas en hueso su momento de aparición habrá que buscarlo en época de Trajano.

\section{CONCLUSIONES}

Por último y a modo de síntesis indicaremos, tal y como ha quedado expresado en este trabajo, que las denominadas acus crinales fueron elementos que aunque no siempre, habitualmente se asociaron al mundo de la mujer, y esencialmente a su peinado. Esta cuestión ha quedado evidenciada tanto por los testimonios arqueológicos como por los de las fuentes clásicas, así como a través de la iconografía. No obstante y pese a que esta se configure como la función principal que debieron desempeñar este tipo de objetos en época romana, debemos indicar que tal y como planteamos en este trabajo pudieron estar dedicadas a otras funciones, no siempre relacionadas con el mundo del peinado.

La gran ausencia de bibliografía que, sobre estos objetos en particular y que sobre la industria de hueso en general, se produce en nuestro país, nos impulsó a profundizar en la bibliografía foránea, lo que nos ofreció una visión mucho más globalizadora de este tipo de producción, llevándonos a comprobar que la morfología de estas se repite en diversos puntos del Imperio. Por esta razón sería muy interesante elaborar un estudio de la 
distribución de estos elementos y el determinar si este fenómeno fue producto de una producción local reproductora de tendencias o modas que imperan en estos momentos o de comercialización de estos productos a gran escala, hecho que parece más lógico.

Desde el punto de vista de la fabricación, nuestras conclusiones han derivado de la simple observación directa de las piezas, lo que nos ha llevado a extraer conclusiones bastante interesantes, aunque sin duda el haber realizado otro tipo de análisis habría enriquecido de manera notable el presente trabajo. De cualquier forma desarrollaremos todas las cuestiones relacionadas con la técnica de fabricación cuando abordemos en profundidad el estudio del posible taller de la «Casa de los Estucos" (Complutum).

Finalmente hemos propuesto una sistematización tipológica de la colección de acus crinales de la ciudad hispanorromana de Complutum, correspondiente a los elementos documentados en campañas de excavación posteriores a 1984, que provienen de contextos bien datados. Con ello esperamos que estos materiales dejen de ser meros números de inventario dentro de las memorias de excavación, y que pasen a ser considerados como un elemento que transcienda del mero objeto o testimonio material para convertirse en una pieza más del engranaje que articula la presencia romana en Hispania.

\section{CATÁLOGO}

-1. Sin cabeza definida, rematada en su extremo de forma llana. Tipo la.

Lon. $110 \mathrm{~mm}$. Diám. máx. $5 \mathrm{~mm}$. Foro de Complutum. Sin contexto determinado. Integra.

-2. Sin cabeza definida, rematada en su extremo de forma llana. Tipo la.

Lon. $71 \mathrm{~mm}$. Diám. máx. $6 \mathrm{~mm}$. Foro de Complutum. Sin contexto determinado. Fragmentada en la punta.

-3. Sin cabeza definida, rematada en su extremo de forma llana. Tipo la.

Lon. 74 mm. Diám. máx. 6 mm. Foro de Complutum. Sin contexto determinado. Fragmentada en la punta.

-4. Sin cabeza definida, rematada en su extremo de forma circular. Tipo lb.

Lon. $69 \mathrm{~mm}$. Diám. máx. 5,2 mm. Foro de Complutum. Sin contexto determinado. Fragmentada en la punta. 
-5. Sin cabeza definida, rematada en su extremo de forma circular. Tipo lb.

Lon. $36 \mathrm{~mm}$. Diám. máx. $3 \mathrm{~mm}$. Foro de Complutum, siglos IV-v d.C. Fragmentada en la punta.

6. Sin cabeza definida, rematada en su extremo de forma circular. Tipo lb.

Lon. $49 \mathrm{~mm}$. Diám. máx. 3,5 mm. Foro de Complutum. Sin contexto determinado. Fragmentada en la punta.

7. Sin cabeza definida, rematada en su extremo de forma ojival. Tipo Ic. Lon. $38,5 \mathrm{~mm}$. Diám. máx. $3.5 \mathrm{~mm}$. Foro de Complutum, siglos IV-v d.C. Fragmentada en el cuerpo.

8. Sin cabeza definida, rematada en su extremo de forma cónica. Tipo Id.

Lon. $60 \mathrm{mmm}$. Diám. máx. $5,7 \mathrm{~mm}$. Foro de Complutum, siglos IV-v d.C. Fragmentada en la punta. Presenta coloración grisacea.

9. Sin cabeza definida, rematada en su extremo de forma cónica. Tipo Id.

Lon. 47 mm. Diám. máx. 7,2. Foro de Complutum, siglos IV-V d.C. Fragmentada en el cuerpo.

10. Sin cabeza definida, rematada en su extremo en forma cónica. Tipo Id.

Lon. 25,5 mm. Diám. máx. 6,2. Foro de Complutum, siglos III-IV d.C. Fragmentada en el cuerpo.

11. Sin cabeza definida, rematada en su extremo de forma cónica. Tipo ld.

Lon. $56 \mathrm{~mm}$. Diám. máx. $6 \mathrm{~mm}$. Casa de los estucos, $2^{\mathrm{a}}$ mitad del siglo / d.C. Integra. Probablemnte reafilada.

12. Sin cabeza definida, rematada en su extremo de forma cónica. Tipo ld.

Lon. $67 \mathrm{~mm}$. Diám. máx. 6mm. Foro de Complutum. Sin contexto determinado. Fragmentada en la punta.

13. Sin cabeza definida, rematada en su extremo de forma cónica. Tipo Id.

Lon. $81 \mathrm{~mm}$. Diám. máx. 5,2. Casa de los estucos. $2^{\mathrm{a}}$ mitad siglo I d.C. Fragmentada en la punta.

14. «De cabeza esférica«. Tipo lla.

Lon. $67 \mathrm{~mm}$. Diám. máx. 5,7 mm. Casa de lo estucos. 2ª mitad siglo । d.C. Integra. 
15. «De cabeza esférica «. Tipo lla.

Lon. $34 \mathrm{~mm}$. Diám. máx. 4,9 mm. Indeterminada. Fragmentada en el cuerpo. Presenta la cabeza muy mal acabada. Sin contexto determinado.

16. «De cabeza esférica» Tipo lla.

Lon. $51 \mathrm{~mm}$. Diám. máx. 5,9 mm. Casa de los estucos. Sin contexto determinado. Fragmentada en la punta.

17. «De cabeza esférica» Tipo lla.

Lon. $66 \mathrm{~mm}$. Diám. máx. 4,5 mm. Casa de los estucos. Sin contexto determinado. Fragmentada en la punta.

18. «De cabeza esférica» Tipo lla.

Lon. $46 \mathrm{~mm}$. Diám. máx. $5 \mathrm{~mm}$. Casa de los estucos. $2^{a}$ mitad siglo I d.C. Fragmentada en la mitad inferior del cuerpo.

19. «De cabeza esférica» Tipo Ila.

Lon. $49 \mathrm{~mm}$. Diám. máx. $4 \mathrm{~mm}$. Casa de los estucos. $2^{\mathrm{a}}$ mitad siglo । d.C. Fragmentada en el cuerpo. Presenta coloración negruzca.

20. «De cabeza esférica» Tipo lla.

Lon. $43 \mathrm{~mm}$. Diám. max. 5,5 mm. Casa de los estucos. $2^{\text {a }}$ mitad siglo । d.C. Fragmentada en el cuerpo. Cabeza seccionada longitudinalmente.

21. «De cabeza esférica» Tipo lla.

Lon. $64 \mathrm{~mm}$. Diám. máx. 5,2 mm. Casa de los estucos. $2^{\text {a }}$ mitad siglo I d.C. Integra.

22. «De cabeza esférica» Tipo lla.

Lon. $67 \mathrm{~mm}$. Diám. máx. 5,5 mm. Casa de los estucos. 2ª mitad siglo 1 d.C. Fragmentada en la punta.

23. «De cabeza esférica» Tipo lla.

Lon. $78 \mathrm{~mm}$. Díam. máx. 5,5 mm. Fuente del Juncal. $1^{a}$ mitad siglo । d.C. Fragmentada en la punta.

24. «De cabeza esférica» Tipo lla.

Lon. $42 \mathrm{~mm}$. Diám. max. $5 \mathrm{~mm}$. Casa de lo estucos. $2^{\text {a }}$ mitad siglo I d.C. Fragmentada en el cuerpo. Cabeza y cuerpo seccionados longitudinalmente. Coloración verdosa.

25. «De cabeza esférica» Tipo Ila.

Lon. $36 \mathrm{~mm}$. Diám. máx. $6 \mathrm{~mm}$. Villa del Val. Finales del siglo III principios del IV d.C. Fragmentada en el cuerpo. 
26. «De cabeza esférica» Tipo lla.

Lon. $82 \mathrm{~mm}$. Diám. máx. $7 \mathrm{~mm}$. Hippolytus. Finales del siglo III principios del iv d.C. Integra.

-27. "De cabeza esférica» Tipo lla.

Lon. $68 \mathrm{~mm}$. Diám. máx. 6,5 mm. Foro de Complutum. Siglos IV-v d.C. Fragmentada en el cuerpo.

28. «De cabeza esférica» Tipo lla.

Lon. $64 \mathrm{~mm}$. Diám. máx. $5 \mathrm{~mm}$. Indeterminado. Fragmentada en la punta.

29. «De cabeza esférica» Tipo lla.

Lon. $56 \mathrm{~mm}$. Diám. máx 4,3 mm. Foro de Complutum, Sin contexto determinado. Fragmentada en la punta.

30. «De cabeza esférica» Tipo lla.

Lon. $60 \mathrm{~mm}$. Diám. máx. $4 \mathrm{~mm}$. Foro de Complutum. Siglos IV-V

d.C. Fragmentada en la punta.

31. «De cabeza esférica» Tipo lla.

Lon. $70 \mathrm{~mm}$. Diám. máx. 5,5 mm. Foro de Complutum. Siglos IV-V d.C. Fragmentada en la punta.

32. «De cabeza esférica» Tipo Ha.

Lon. $37 \mathrm{~mm}$. Diám. máx. $7 \mathrm{~mm}$. Foro de Complutum. Siglos IV-V

d.C. Fragmentada en el cuerpo.

33. "De cabeza esférica» Tipo lla.

Lon. $42 \mathrm{~mm}$. Diám. máx. 3,5 mm. Foro de Complutum. Siglos IV-V

d.C. Fragmentada en el cuerpo. Coloración verdosa.

34. «De cabeza esférica» Tipo lla.

Lon. $70 \mathrm{~mm}$. Diám. máx. $5 \mathrm{~mm}$. Indeterminada. Sin contexto determinado. Fragmentada en la punta.

- 35. «De cabeza esférica» Tipc lla.

Lon. 39,3 mm. Diám. máx. 5,2 mm. Foro de Complutum. Siglos Iv$\checkmark$ d.C. Muy fragmentada.

36. «De cabeza esférica» Tipo lla.

Lon. $63 \mathrm{~mm}$. Diám. máx. 4,5 mm. Indeterminada. Sin contexto determinado. Fragmentada en la punta.

37. «De cabeza esférica» Tipo lla.

Lon. 50,5 mm. Diám. máx. $6 \mathrm{~mm}$. Indeterminada. Sin contexto determinado. Fragmentada en la punta. 
38. «De cabeza esférica» Tipo lla.

Lon. $55 \mathrm{~mm}$. Diám. máx. $5 \mathrm{~mm}$. Indeterminada. Sin contexto determinado. Fragmentada en la punta.

39. «De cabeza esférica» Tipo Ila.

Lon. $69 \mathrm{~mm}$. Diám. máx. 6,8 mm. Indetermínada. Sin contexto determinado. Fragmentada en la punta. Carece del engrosamiento en la parte superior del cuerpo.

40. «De cabeza esférica» Tipo lla.

Lon. $58 \mathrm{~mm}$. Diám. máx. $7 \mathrm{~mm}$. Foro de Complutum. Siglos IV-V d.C. Fragmentada en la punta.

41. «De cabeza esférica» Tipo lla.

Lon. 46 mm. Diám. máx. 4,8 mm. Foro de Complutum. Siglos Iv-V d.C. Fragmentada en la punta.

42. "De cabeza esférica» Tipo lla.

Lon. $45 \mathrm{~mm}$. Diám. máx. 3,5 mm. Foro de Complutum. Siglos Iv-v d.C. Fragmentado en la punta.

43. «De cabeza esférica» Tipo lla.

Lon. $56 \mathrm{~mm}$. Diám. máx. $4 \mathrm{~mm}$. Indeterminada. Sin contexto determinado. Fragmentado en la punta.

44. “De cabeza esférica» Tipo lla.

Lon. $43 \mathrm{~mm}$. Diám. máx. $6 \mathrm{~mm}$. Dehesa. $2^{\mathrm{a}}$ mitad del siglo IV d.C. Fragmentado en el cuerpo.

45. «De cabeza esférica» Tipo lla.

Lon. $59 \mathrm{~mm}$. Diám. máx. 6,8. Foro de Complutum, Sin contexto determinado. Integra. Esta reafilada.

46. «De cabeza esférica y cuello marcado» Tipo lib.

Lon. $87 \mathrm{~mm}$. Diám. máx. 5,6 mm. Casa de los estucos. $2^{2}$ mitad del siglo I d.C. Integra.

47. «De cabeza esférica y cuello marcado» Tipo llb.

Lon. $59 \mathrm{~mm}$. Diám. máx. $4 \mathrm{~mm}$. Casa de los estucos, Sin contexto determinado. Fragmentada en la punta. Color verdoso.

48. «De cabeza esférica y cuello marcado» Tipo llb.

Lon. $59 \mathrm{~mm}$. Diám. máx. $4 \mathrm{~mm}$. Casa de los estucos. 2ª mitad del siglo I d.C. Fragmentado en la punta.

49. «De cabeza esférica y cuello marcado» Tipo Ilb.

Lon. $55,5 \mathrm{~mm}$. Diám. máx. 5,5 mm. Villa del Val, Sin contexto determinado. Fragmentada en la punta. La cabeza tiene sección ovalada. 
50. «De cabeza esférica y cuello marcado» Tipo llb. Lon. $61,5 \mathrm{~mm}$. Diám. máx. $5 \mathrm{~mm}$. Villa del Val. Finales del siglo III o principios del IV d.C. Fragmentada en la punta.

-51. «De cabeza esférica y cuello marcado» Tipo IIb. Lon. $68 \mathrm{~mm}$. Diám. máx. 4,1 mm. Foro de Complutum. Siglos IV-V d.C. Fragmentada en la punta.

52. «De cabeza esférica y cuello marcado" Tipo llb.

Lon. $58 \mathrm{~mm}$. Diám. máx. $5 \mathrm{~mm}$. Foro de Complutum. Siglos IV-v d.C. Fragmentada en la punta.

- 53. «De cabeza esférica y cuello marcado» Tipo Ilb.

Lon. $69 \mathrm{~mm}$. Diám. máx. $3 \mathrm{~mm}$. Foro de Complutum. Siglos Iv-v d.C. Fragmentada en la punta.

- 54. «De cabeza esférica y cuello marcado» Tipo Ilb.

Lon. $39 \mathrm{~mm}$. Diám. máx. 4,1 mm. Foro de Complutum. Siglos IV-V d.C. Fragmentada en al cuerpo.

55. «De cabeza esférica y de cuello marcado» Tipo Ilb.

Lon. $62 \mathrm{~mm}$. Diám. máx. 5,7 mm. Foro de Complutum. Siglos IV-v d.C. Fragmentada en la punta. Cabeza seccionada longitudinalmente. Coloración verdosa.

56. "De cabeza esférica y cuello marcado» Tipo llb.

Lon. $36 \mathrm{~mm}$. Diám. máx. $5 \mathrm{~mm}$. Indeterminada. Sin contexto determinado. Fragmentada en el cuerpo.

57. «De cabeza esférica y cuello marcado» Tipo llb.

Lon. $37 \mathrm{~mm}$. Diám. máx. $4 \mathrm{~mm}$. Indeterminada. Sin contexto determinado. Fragmentada en el cuerpo.

58. «De cabeza esférica y cuello marcado» Tipo llb.

Lon. $92 \mathrm{~mm}$. Diám. máx. $6 \mathrm{~mm}$. Foro de Complutum. Siglos IV-V d.C. Integra.

59. "De cabeza esférica y cuello marcado» Tipo llb.

Lon. $54 \mathrm{~mm}$. Diám. máx. $5,4 \mathrm{~mm}$. Villa del Val. Sin contexto determinado. Fragmentada en la punta.

60. «De cabeza oval» Tipo III.

Lon. $77 \mathrm{~mm}$. Diám. máx. $4 \mathrm{~mm}$. Casa de los estucos. $2^{\mathrm{a}}$ mitad del siglo I d.C. Integra.

61. «De cabeza oval» Tipo III.

Lon. $31 \mathrm{~mm}$. Diám. máx. 3,5 mm. Foro de Complutum, Sin contexto determinado. Fragmentada en el cuerpo. 
62. «De cabeza oval» Tipo III.

Lon. 28,5 mm. Diám. máx. 3,3 mm. Foro de Complutum, Sin contexto determinado. Fragmentada en el cuerpo. Cabeza seccionada longitudinalmente.

63. «De cabeza oval» Tipo III.

Lon. $58,5 \mathrm{~mm}$. Diám. máx. $3 \mathrm{~mm}$. Foro de Complutum, Sin contexto determinado. Fragmentada en la punta.

64. «De cabeza oval» Tipo III.

Lon. $75 \mathrm{~mm}$. Diám. máx. 4,5 mm. Foro de Complutum. Siglos $\mathrm{N}-\mathrm{v}$

d.C. Fragmentada en la punta.

65. «De cabeza oval» Tipo III.

Lon. $46 \mathrm{~mm}$. Diám. máx. 4,1 mm. Indeterminada. Sin contexto determinado. Fragmentada en la punta.

66. «De cabeza oval» Tipo III.

Lon. $43 \mathrm{~mm}$. Diám. máx. $4 \mathrm{~mm}$. Foro de Complutum. Siglos III-IV d.C. Fragmentada en la punta.

67. «De cabeza oval» Tipo III.

Lon. $72 \mathrm{~mm}$. Diám. máx. 4,1 mm. Villa del Val. Siglos III-IV d.C.

Fragmentada en la punta.

68. «De cabeza oval» Tipo III.

Lon. $67 \mathrm{~mm}$. Diám. máx. 5,9 mm. Foro de Complutum. Siglo IV-v d.C. Fragmentada en la punta.

69. «De cabeza oval» Tipo III.

Lon. $69 \mathrm{~mm}$. Diám. máx. 4,7 mm. Villa del Val. Siglos III-IV d.C. Integra.

70. «De cabeza oval» Tipo III.

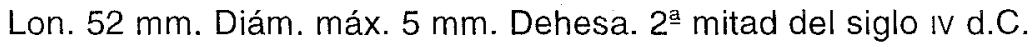
Fragmentada en la punta.

-71. «De cabeza oval» Tipo III.

Lon. $79 \mathrm{~mm}$. Diám. máx. $6 \mathrm{~mm}$. Casa de los estucos. $2^{\underline{a}}$ mitad del siglo ı d.C. Integra.

- 72. «De cabeza oval» Tipo III.

Lon. $66 \mathrm{~mm}$. Diám. máx. $5 \mathrm{~mm}$. Casa de los estucos. Sin contexto determinado. Fragmentada en la punta.

- 73. «De cabeza oval» Tipo III.

Lon. 94,5 mm. Diám. máx. $4 \mathrm{~mm}$. Hippolytus. $2^{\mathrm{a}}$ mitad del siglo 1 d.C. Integra. 
- 74. «De cabeza oval» Tipo III.

Lon. $67 \mathrm{~mm}$. Diám. máx. $3 \mathrm{~mm}$. Casa de los estucos. $2^{\mathrm{a}}$ mitad del siglo I d.C. Fragmentada en la punta. Coloración negruzca.

75. «De cabeza oval» Tipo III.

Lon. $88 \mathrm{~mm}$. Diám. máx. 3,2 mm. Casa de los estucos. $2^{2}$ mitad del siglo । d.C. Fragmentada en la punta.

- 76. «De cabeza oval» Tipo III.

Lon. $67 \mathrm{~mm}$. Diám. máx. $3 \mathrm{~mm}$. Hippolytus. Finales del siglo 1110 principios del Iv d.C. Integra.

77. «De cabeza oval» Tipo III.

Lon. $29 \mathrm{~mm}$. Diám. máx. $3,7 \mathrm{~mm}$. Casa de los estucos. $2^{-a}$ mitad del siglo 1 d.C. Fragmentada en el cuerpo.

-78. «De cabeza semiesférica» Tipo IV.

Lon.76 mm. Diám. máx. $4 \mathrm{~mm}$. Foro de Complutum. Siglos IV-V d.C. Fragmentado en la punta.

79. «De cabeza semiesférica» Tipo IV.

Lon. $113 \mathrm{~mm}$. Diám. máx. $5 \mathrm{~mm}$. Casa de los estucos. $2^{2}$ mitad del siglo I d.C. Fragmentada en la cabeza.

80. «De cabeza cónica y cuello rebajado» Tipo $V$.

Lon. 107,5 mm. Diám. máx. 5,7 mm. Casa de los estucos, Sin contexto determinado. Integra.

81. «De cabeza cónica y cuello rebajado» Tipo $V$.

Lon. $86,5 \mathrm{~mm}$. Diám. máx. 5,5 mm. Hippolytus. A partir del último cuarto del siglo । d.C. Fragmentada en la punta.

82. «De cabeza cónica y cuello rebajado» Tipo V.

Lon. $62 \mathrm{~mm}$. Diám. máx. 5,8 mm. Foro de Complutum. Siglos IV-V d.C. Fragmentada en la punta. Coloración verdosa.

83. «De cabeza cónica y cuello rebajado» Tipo V.

Lon. $52 \mathrm{~mm}$. Diám. máx. $5 \mathrm{~mm}$. Foro de Complutum. Siglos IV-v d.C. Fragmentada en la mitad del cuerpo.

84. «De cabeza bicónica o lenticular» Tipo VI.

Lon. $62 \mathrm{~mm}$. Diám. máx. 5,9 mm. Casa de los Estucos. 2a mitad del siglo I d.C. Fragmentada en la punta.

85. «De cabeza bicónica o lenticular» Tipo VI.

Lon. $29 \mathrm{~mm}$. Diám. máx. $5 \mathrm{~mm}$. Foro de Complutum. Siglos IV-V d.C. Fragmentada en el cuerpo. 
86. «De cabeza discoidal» Tipo VII.

Lon. $81 \mathrm{~mm}$. Diám. máx. $4 \mathrm{~mm}$. Indeterminada. Sin contexto determinado. Fragmentada en la punta.

87. «De cabeza discoidal» Tipo VII.

Lon. $48 \mathrm{~mm}$. Diám. máx. $4,7 \mathrm{~mm}$. Casa de los estucos. Sin contexto determinado. Fragmentada en la punta.

88. «De cabeza poligonal» Tipo VIII.

Lon. $100 \mathrm{~mm}$. Diám. máx. $7 \mathrm{~mm}$. Mosaico de los Cupidos. Sin contexto determinado. Integra.

89. «De cabeza triangular o apuntada» Tipo IX.

Lon. $70 \mathrm{~mm}$. Diám. máx. $8 \mathrm{~mm}$. Hippolytus. Finales del siglo। d.C. o principios del II d.C. Fragmentada en la punta. La sección de la cabeza es triangular.

90. «De cabeza triangular o apuntada» Tipo IX.

Lon. $41 \mathrm{~mm}$. Diám. máx. 3,5 mm. Foro de Complutum. Sin contexto determinado. Fracturada en el cuerpo. La sección de la cabeza es oval.

91. "De cabeza triangular o apuntada" Tipo IX.

Lon. $31,5 \mathrm{~mm}$. Diám. máx. $2 \mathrm{~mm}$. Casa de los estucos. $2^{\mathrm{a}}$ mitad del siglo I d.C. Fracturada en el cuerpo. La sección de la cabeza es plana.

92. «De cabeza parabólica» Tipo X.

Lon. $48 \mathrm{~mm}$. Diám. máx. 8,7 mm. Foro de Complutum. Siglos IV-V d.C. Fragmentada en la punta. Decoración incisa en la cabeza. El cuerpo carece del engrosamiento carcterístico.

93. «De cabeza cilíndrica» Tipo XI.

Lon. $54 \mathrm{~mm}$. Diám. máx. 2,5 mm. Foro de Complutum. Siglos IV-V d.C. Integra.

- 94. «De cabeza prismática» Tipo XII.

Lon. $34 \mathrm{~mm}$. Diám. máx. $3 \mathrm{~mm}$. Foro de Complutum. Siglos IV-V d.C. Fragmentada en la parte inferior del cuerpo.

-95. «De cabeza fusiforme» Tipo XIII.

Lon. $88 \mathrm{~mm}$. Diám. máx. $6 \mathrm{~mm}$. Dehesa, Sin contexto determinado. Fragmentada en la cabeza. Cuello moldurado con cuatro anillos superpuestos. No conserva la cabeza.

96. «De cabeza fusiforme» Tipo XIII.

Lon. $89 \mathrm{~mm}$. Diám. máx. $6 \mathrm{~mm}$. Foro de Complutum, Sin contexto determinado. Integra. Cabeza en forma de Huso que asienta sobre cuatro anillos que articulan la decoración del cuello. 
97. «De cabeza fusiforme» Tipo XIII.

Lon. $74 \mathrm{~mm}$. Diám. máx. $6 \mathrm{~mm}$. Hippolytus. Finales del siğlo III o principios del IV d.C. Fragmentada en la punta. Presenta el huso decorado mediante incisiones oblicuas. La cabeza asienta sobre cuatro molduras del tipo de toros.

98. "De cabeza fusiforme» Tipo XIII.

Lon. $62 \mathrm{~mm}$. Diám. máx $4,9 \mathrm{~mm}$. Villa del Val. Finales del siglo III o principios del IV d.C. Fragmentada en la cabeza y la punta. Cuello decorado a base de dos toros y una escocia.

99. «De cabeza zoomorfa» Tipo XIV.

Lon. $41 \mathrm{~mm}$. Diám. máx $4 \mathrm{~mm}$. Casa de los Estucos. $2^{\mathrm{a}}$ mitad del siglo I d.C. Fragmentada en la parte inferior del cuerpo. Cabeza zoomorfa representando un animal no identificado.

100. «De cabeza antropomorfa» Tipo XV.

Lon. 43,5 mm. Diám. máx $6 \mathrm{~mm}$. Foro de Complutum. $2^{\mathrm{a}}$ mitad del siglo 1 d.C. Fragmantada en la cabeza y en el cuerpo. Representación de un busto probablemente femenino del que hemos perdido la cabeza.

101. «Indeterminado»

Lon. $7 \mathrm{~mm}$. Diám. máx 7,5 mm. Hippolytus. Contexto de época moderna y contemporánea. Fragentada en cabeza y cuerpo. Restos de uria moldura en forma de toro en el cuello.

102 «Indeterminado»

Lon. $48 \mathrm{~mm}$. Diám. máx $8 \mathrm{~mm}$. Foro de Complutum, Sin contexto determinado. Fragmentada en cabeza y cuerpo. Decoración incisa de motivos lineales y de zig-zag en torno al cuerpo.

103 Posible «Ligula» o «aplicador»

Lon. $38 \mathrm{~mm}$. Diám. máx $3 \mathrm{~mm}$. Foro de Complutum, Sin contexto determinado. Fragmentada en el cuerpo.

\section{BIBLIOGRAFIA}

Alarçao, M., Etienne, R., Moutinho, A. y Ponte, S. (1979): Fouilles de Conimbriga VII. Trouvailles diverses. Conclusions génerales, París.

ApulEIUs: The golden ass. Trad. Adlington, W. The Loeb Classical Library. 1977.

ÁvILA FrançA, E. (1968): "Alfiletes de toucado romanos de Conimbriga", Conimbriga, VIl, pp. 129.

BEAL, J.C. (1983a): Catalogue des objets de tabletterie du Musée de la civilisation GalloRomaine de Lyon, Lyon.

BEAL, J.C. (1983b): «Les ateliers Gallo-Romains de tabletterie à Lyon et à Vienne», Latomus 42, pp. 607-618. 
BEAL, J.C. (sin fecha): "Les objets en os et en ivoire», Musées de la ville de Vienne, pp. 1-31. BEAL, J.C. (1984): Les objets de tabletterie antique du Musée Archaeologique de Nimes. Nîmes. BECKMANN, B. (1966): "Studien über die metallnadeln der romischen kaiserzeit im freiem Germanien", Saulbur-dahrbuch, XXIII.

Borobia MELENDO, E.L. (1988): Instrumental médico-quirúrgico de la Hispania romana Madrid. CRumMY, N. (1979): «A cronology of Romano-British Bone Pins», Britannia, 10, pp. 157-163.

DAREMberG, M. CH., y SAGLIO E. (1969): Dictionnaire des antiquités grecques et Romaines, Graz.

Fernández-Galiano Ruiz, D. (1976): Carta Arqueológica de Alcalá de Henares. Madrid.

Fefinández-Galiano Ruiz, D. (1984): Complutum /. Excavaciones, Excavaciones Arqueológicas en España, 137, Madrid.

ISIDORO DE SEVILLA: Etimologias. Ed. Oroz, Trad. de Reta, J. y Marcos Casquero, M.A., Madrid, 1983.

JOHNSON, D.E. (1972): «A roman building at Chalk, near Gravesend», Britannia, III.

JuVEnAl: Sátiras. Trad. de Manuel Balasch. Ed. Gredos, Madrid, 1991.

KIELLING, L., y SUSKIN, A. (1951): Index verborum luvenalis. North Caroline.

LADJIMI-SebAl, L. (1985): "El adorno femenino en África. Época romana». Revista de Arqueología, 50, Madrid, pp. 55-64.

MacGiegor, A. (1985): Bone, antler, ivory \& horn. The technology of skeletal materials since roman period. New Jersey.

MARCIAL: Epigramas completos. Trad. de Dulce Estefania. Ed. Cátedra. Madrid.

MARCIAL: Epigrams. Trad. Walter, C.A. \& Ker, M.A., London. Harward University Press.

MARINÉ, M. (1983): “Moda y épocas en el peinado romano». Revista de Arqueología, 24, Madrid, pp. 57-65.

Méndez Madariaga, A., y Rascón Marqués, S. (1989): Los visigodos en alcalá de Henares, Cuadernos del Juncal, 1, Alcalá de Henares.

Ovidio, Publio Nasón: Amores. Medicamina faciei feminae. Ars amatoria. Remedia amoris. E.J. Kenney ed.

Ovidio: Arte de amar. Remedios contra el amor. Cosméticos para el rostro femenino. Montero Cartelle, E., Ed. Akal/Clásica, Madrid, 1987.

Ovidio: Amores. Trad. de Palacios Martín, A., Badajoz, 1988.

Petronius: Satiricón. Trad. Rodríguez Santidrian, P. Madrid, 1987.

POlO LóPEZ, J. (1995): "Un nuevo mosaico con el tema de cupidos procedente de Complutum», Xenia, 3-16.

Rascón Marqués, S.; Polo lópez, J.; Méndez Madariaga, A., Y Gómez Pallarés, J. (1995): «Hippolytus: estudio de un nuevo mosaico del género de pesca y con inscripción procedente de Complutum - Alcalá de Henares, Madrid-». Lucentum (en prensa).

Rascón Marqués, S.; POlo López, J., y MAESo, Må. D. (1996): «Grafitos sobre Terra Sigillata Hispánica hallados en un vertedero del siglo I en la casa de Hippolytus (Complutum)". Cuadernos de Prehistoria y Arqueología de la Universidad Autónoma de Madrid (en prensa).

RASCÓN MARQUÉS, S. (1995): La ciudad hispanorromana de Complutum. Cuadernos del Junal, 2. Alcalá de Henares.

STEvENSON, R.B.K. (1955): «Pins and the cronology of the brochs", Procedings of the prehistoric society, Vol XXI, pp. 283-295.

VIANA, A. (1944); “O fabrico do acus Crinalis de osso», Broteria, XXXVIII, 4, pp. 394-401. 